\title{
Research on Collapse Process of Cable-Stayed Bridges under Strong Seismic Excitations
}

\author{
Xuewei Wang, ${ }^{1}$ Bing Zhu, ${ }^{1}$ and Shengai Cui ${ }^{2}$ \\ ${ }^{1}$ Department of Bridge Engineering, School of Civil Engineering, Southwest Jiaotong University, Chengdu, Sichuan 610031, China \\ ${ }^{2}$ Department of Building Materials, School of Civil Engineering, Southwest Jiaotong University, Chengdu, Sichuan 610031, China \\ Correspondence should be addressed to Bing Zhu; zhubing126@126.com
}

Received 17 March 2017; Revised 12 May 2017; Accepted 22 May 2017; Published 28 June 2017

Academic Editor: Mahmoud Bayat

Copyright (c) 2017 Xuewei Wang et al. This is an open access article distributed under the Creative Commons Attribution License, which permits unrestricted use, distribution, and reproduction in any medium, provided the original work is properly cited.

\begin{abstract}
In order to present the collapse process and failure mechanism of long-span cable-stayed bridges under strong seismic excitations, a rail-cum-road steel truss cable-stayed bridge was selected as engineering background, the collapse failure numerical model of the cable-stayed bridge was established based on the explicit dynamic finite element method (FEM), and the whole collapse process of the cable-stayed bridge was analyzed and studied with three different seismic waves acted in the horizontal longitudinal direction, respectively. It can be found from the numerical simulation analysis that the whole collapse failure process and failure modes of the cable-stayed bridge under three different seismic waves are similar. Furthermore, the piers and the main pylons are critical components contributing to the collapse of the cable-stayed bridge structure. However, the cables and the main girder are damaged owing to the failure of piers and main pylons during the whole structure collapse process, so the failure of cable and main girder components is not the main reason for the collapse of cable-stayed bridge. The analysis results can provide theoretical basis for collapse resistance design and the determination of critical damage components of long-span highway and railway cable-stayed bridges in the research of seismic vulnerability analysis.
\end{abstract}

\section{Introduction}

In recent years, with the rapid development of bridges construction, bridge collapse accidents were often reported in the last few years. The causes of bridges collapse are various that can be divided into two categories: human factors and natural factors $[1,2]$. Human factors mainly include the unreasonable design and construction, improper management, ships impact, and cars' impact. Natural factors mainly are made up of earthquake, flood, wind, rain and debris (ice) impact, and so on. The bridge collapse accidents caused by earthquake account for the largest proportion among all the factors with the proportion of $20 \%$ [2]. Fortytwo bridge structures were significantly damaged during the San Fernando earthquake in 1971 (counting twin freeway bridges as single structures), including five that collapsed [3]. The most dramatic damage occurred to overpass structures at three major interchanges. These three interchanges are all in the region of strong shaking. This earthquake was the primary reason for the US congress to establish the
National Earthquake Hazard Reduction Program (NEHRP) in 1977. During the Kobe earthquake in 1995, according to the Japan road association (JRA) earthquake damage investigation results, there were 320 bridges damaged, of which about 27 bridge suffered serious damage [4]. Some viaduct collapsed and the famous Shinkansen railway and three expressways completely interrupted, resulting in great losses. During Taiwan Chi-Chi earthquake in 1999 [5-7], the ground motion acceleration was $0.5 \mathrm{~g} \sim 0.6 \mathrm{~g}$ near the near fault, resulting in many bridges being collapsed and damaged in central region of Taiwan. Particularly, a large cablestayed bridge constructed of prestressed concrete girders (PC cable-stayed bridge) located about $6 \mathrm{~km}$ from the epicenter was damaged seriously by the seismic excitation. During Wenchuan earthquake in 2008 [8,9], the economic losses were enormous. Roads and infrastructure in Wenchuan Town near the epicenter were heavily damaged, especially the bridges on National Highway 213 and on the DujiangyanWenchuan expressway. After Wenchuan earthquake, 1657 bridges in Sichuan Province were investigated, of which about 
130 bridges were damaged or collapsed. On 11 March, 2011, the great east Japanese earthquake induced a huge tsunami. The natural disaster hit the northeastern part of Japan and caused infrastructure damaged seriously and a severe nuclear crisis [10]. The number of bridges washed out was about 300 [11].

In order to evaluate the seismic capacity of bridge structures under strong earthquakes and to reduce damage to bridge structures, many scholars did a lot of research work on seismic vulnerability analysis of bridge structures [12-18]. However, the determination of critical damage components of bridge structures is one of the key problems in seismic vulnerability analysis. Therefore, it is necessary to study the collapse modes and failure mechanism of bridge structures under strong excitation to obtain the critical damage components. For example, Kunnath and Gross [19] established the model of a typical double-deck bent of the Cypress Viaduct which collapsed during the 1989 Loma Prieta earthquake consisting of spread plasticity-based beam-column elements to represent the piers and deck and shear panel elements to represent the pedestal region. The inelastic damage evaluation of the typical double-deck bent of the Cypress Viaduct was obtained. Zayati et al. [20] built a one-third scale model of a retrofit bent (Bent B-8) from the Alemany Freeway (I280101 interchange) which was tested at the structures laboratory at the University of California at Berkeley. The experimental studies were required to address the uncertainties inherent in the design and examine the repairability of the retrofit structure following a major earthquake. Xie and Sun [21] studied the dynamic response of long-span and high-pier continuous rigid-frame bridges under strong earthquake with damage model of reinforced concrete by the explicit dynamic analysis method. Wibowo [22] presented results of a study on earthquake response analysis of bridges by using the Applied Element Method that allows separation of structural members or components due to fracture failure and the effects of contact and inertial forces caused by the falling debris. The analysis is able to predict the initiation of collapse, progression of collapse, and the final collapse mechanisms. Zong et al. [23] presented the results of a study in which a 1:15 scaled two-span prestressed concrete continuous rigid-frame bridge model with box-type piers was tested using the shake-table array test system to investigate the seismic response characteristics. Two nonlinear finite element (FE) models were constructed to simulate the seismic response under weak seismic waves and to simulate the collapse and failure mechanisms of the scaled bridge under strong earthquakes, respectively. Li et al. [24] established a simplified numerical model of RC continuous girder bridge with finite element method. The collapse processes of a RC continuous girder bridge with various bearing strength under strong earthquakes are simulated, and the collapse modes of the bridge are analyzed. Xie et al. [25] and Song [26] did the research on the collapse mechanisms of arch bridges by finite element method. Shoji et al. [6, 7] did the research on the failure mechanisms associated with the seismic response of a long-period cable-stayed bridge structure when subjected to a long-period seismic excitation based on the numerical method and shaking table tests. Yoo et al. [27] proposed a new and simple method for estimating the collapse load of a steel cable-stayed bridge. The results demonstrate that the proposed method is a good substitute for a complex nonlinear inelastic analysis to approximately evaluate the collapse loads as well as failure modes of steel cable-stayed bridges. Duan et al. [28] presented the collapse analysis of a 2D mockup bridge scaled from an actual cable-stayed bridge. The entire processes of the structural damage and collapse were successfully simulated by the proposed method VFIFE. This study provided a foundation for seismic damage prediction and anticollapse seismic design for cable-stayed bridges. Zong et al. [29] and Zhou et al. [30] in order to study the seismic characteristics of cable-stayed bridge with single tower show that a 1:30 scaled model of a semifloating composite cable-stayed bridge was designed and tested on the shaking tables under multisupport excitations with different strong earthquake waves. An implicit integration finite element model and an explicit integration finite element model were established to simulate the seismic responses and failure modes of a cable-stayed bridge model with single tower in shaking table tests. Zong et al. [31] proposed the corresponding components failure criteria and structural collapse failure criteria based on the shaking table testing of a cable-stayed bridge model and explicit integration finite element model with LS-DYNA software.

But above all, the shaking table test method and implicit finite element method were usually used in the studies on collapse process and damage mechanism of bridges under seismic excitations. However, the collapse failure modes of scale bridges model observed by using the shaking table test method may be different from that of full-size bridges under actual seismic excitations. Meanwhile the progressive collapse process is difficult to obtain based on the nonlinear analysis method of implicit integration, because the implicit integration method can not simulate the larger displacement of bridges during the collapse process. Furthermore, the studies on collapse process and damage mechanism of cablestayed bridges are few. So, in this study Pingtan Straits rail-cum-road steel truss cable-stayed bridge was selected as an engineering example to research the collapse modes and the failure mechanism based on the explicit dynamic finite element method by the software LS-DYNA which can simulate large displacement of structure and the failure of components during the collapse process. The whole collapse process of Daxiao Liandao waterway cable-stayed bridge was analyzed and studied with three different seismic waves acting in the horizontal longitudinal direction, respectively.

\section{The Analysis Method of Collapse Failure}

\subsection{The Theoretical Basis of Explicit Dynamic Finite Element Method}

2.1.1. The Finite Element Equations Based on Variational Principle. The basic equations of three-dimensional elastodynamic are as follows:

Equilibrium equation:

$$
\left.\sigma_{i j, j}+f_{i}-\rho \ddot{u}_{i}-\mu \dot{u}_{i}=0 \quad \text { (in } V \text { domain }\right)
$$


Geometric equation:

$$
\left.\varepsilon_{i j}=\frac{1}{2}\left(u_{i, j}+u_{j, i}\right) \quad \text { (in } V \text { domain }\right) .
$$

Physical equation:

$$
\left.\sigma_{i j}=2 G \varepsilon_{i j}+\lambda \delta_{i j} \varepsilon_{k k} \quad \text { (in } V \text { domain }\right) .
$$

Boundary conditions:

$$
\begin{aligned}
u_{i} & =\bar{u}_{i} \quad\left(\text { on } s_{u} \text { boundary }\right) . \\
\sigma_{i j} n_{j} & =\bar{t}_{i} \quad\left(\text { on } s_{\sigma} \text { boundary }\right)
\end{aligned}
$$

Initial conditions:

$$
\begin{aligned}
& u_{i}(x, y, z, 0)=u_{i}(x, y, z), \\
& \dot{u}_{i}(x, y, z, 0)=\dot{u}_{i}(x, y, z),
\end{aligned}
$$

where $\sigma_{i j}$ is second-order stress tensor; $\varepsilon_{i j}$ is second-order strain tensor; $u_{i}$ is first-order displacement tensor; $f_{i}$ is firstorder volume force tensor; $\bar{t}_{i}$ is first-order area force tensor; $n_{j}$ is first-order normal tensor; " $i$ " and ",j" are derivatives of independent coordinate variables; " $\dot{u}_{i}$ " and " $\ddot{u}_{i}$ " are first-time derivative and second-time derivative of displacement; $\rho$ is mass density; $\mu$ is damping coefficient; $G$ is Lamé constant, $G=E / 2(1+\nu)$, and $\lambda=E \nu /(1+\nu)(1-2 \nu) ; \delta_{i j}$ is Kronecker symbol; $s_{u}$ is displacement boundary; $s_{\sigma}$ is force boundary; $V$ is space domain.

The equivalent integral expression of the Galerkin formulation based on (1) and (5) can be described as

$$
\begin{array}{r}
\int_{V} \delta u_{i}\left(\sigma_{i j, j}+f_{i}-\rho \ddot{u}_{i}-\mu \dot{u}_{i}\right) d V \\
-\int_{s_{\sigma}} \delta u_{i}\left(\sigma_{i j} n_{j}-\overline{t_{i}}\right) d S=0,
\end{array}
$$

where weight functions are real displacement variation, $\delta u_{i}$, and boundary value (negative), respectively. It is continuously derivable, because $\delta u_{i}$ is the real displacement variation. Meanwhile $\delta u_{i}$ equals zero on the given displacement boundary of $s_{u}$.

The integration by part is performed to the first term of the volume integration of (7), the stress tensor is symmetric tensor, and we can get

$$
\begin{aligned}
\int_{V} \delta u_{i} \sigma_{i j, j} d V= & \int_{V}\left(\delta u_{i} \sigma_{i j}\right)_{, j} d V \\
& -\int_{V} \frac{1}{2}\left(\delta u_{i, j}+\delta u_{j, i}\right) \sigma_{i j} d V \\
= & -\int_{V} \frac{1}{2}\left(\delta u_{i, j}+\delta u_{j, i}\right) \sigma_{i j} d V \\
& +\int_{s_{\sigma}} \delta u_{i} \sigma_{i j} n_{j} d S .
\end{aligned}
$$

We can know from (2) that virtual strain $\delta \varepsilon_{i j}=1 / 2\left(\delta u_{i, j}+\right.$ $\delta u_{j, i}$ ). Then substituting the expression into (8) and then substituting (8) back into (7), so the variational principle of original problems can be obtained. Due to the dynamic analysis, the dynamic load is changing all over time, so the real state of any time period $\left(t_{1}, t_{2}\right)$ will satisfy the stationary value conditions of

$\delta \Pi(u)$

$$
\begin{aligned}
& =\int_{t_{1}}^{t_{2}}\left[\int_{V}\left(\delta \varepsilon_{i j} \sigma_{i j}+\delta u_{i} \rho \ddot{u}_{i}+\delta u_{i} \mu \dot{u}_{i}-\delta u_{i} f_{i}\right) d V\right. \\
& \left.-\int_{s_{\sigma}} \delta u_{i} \overline{t_{i}} d S\right] d t=0 .
\end{aligned}
$$

In order to calculate the stationary value of functional equations by FEM directly, the structure needs special discretization, and displacement interpolation is applied to the discretization elements and nodes.

The displacement interpolation $u_{i}(i=1,2,3)$ can be expressed in the form of

$$
u_{i}(x, y, z, t)=N_{I}(x, y, z) u_{i I}(t),
$$

where $N_{I}$ is the shape function of the node $I$ and subscript repeat means the summation within its value scope. The matrix form can be written as

$$
\mathbf{u}=\mathbf{N U} \text {. }
$$

We can also obtain the following expressions from (11):

$$
\begin{aligned}
\delta \mathbf{u} & =\mathbf{N} \delta \mathbf{U}, \\
\dot{\mathbf{u}} & =\mathbf{N} \dot{U}, \\
\ddot{\mathbf{u}} & =\mathbf{N} \ddot{\mathbf{U}} .
\end{aligned}
$$

And the matrix forms of the geometric equation and physical equation are

$$
\begin{gathered}
\boldsymbol{\sigma}=\mathrm{D} \boldsymbol{\varepsilon}, \\
\boldsymbol{\varepsilon}=\mathrm{BU} .
\end{gathered}
$$

Equation (14) can be obtained by substituting (12) and (13) into (9).

$$
\begin{aligned}
\delta \Pi & =\int_{t_{1}}^{t_{2}}\left[\int_{V} \mathbf{B}^{T} \mathbf{D B} d V \cdot \mathbf{U}+\int_{V} \mathbf{N}^{T} \rho \mathbf{N} d V \cdot \ddot{\mathbf{U}}\right. \\
& \left.+\int_{V} \mathbf{N}^{T} \mu \mathbf{N} d V \cdot \dot{\mathbf{U}}-\int_{V} \mathbf{N}^{T} \mathbf{f} d V-\int_{s_{\sigma}} \mathbf{N}^{T} \mathbf{t} d S\right] \\
& \cdot \delta \mathbf{U} d t=0 .
\end{aligned}
$$

Assume

$$
\begin{aligned}
& \mathbf{M}^{e}=\int_{V_{e}} \mathbf{N}^{T} \rho \mathbf{N} d V, \\
& \mathbf{C}^{e}=\int_{V_{e}} \mathbf{N}^{T} \mu \mathbf{N} d V, \\
& \mathbf{K}^{e}=\int_{V_{e}} \mathbf{B}^{T} \mathbf{D B} d V, \\
& \mathbf{Q}^{e}=\int_{V_{e}} \mathbf{N}^{T} \mathbf{f} d V+\int_{s_{\sigma}^{e}} \mathbf{N}^{T} \mathbf{t} d S .
\end{aligned}
$$


The mass matrix, the damping matrix, the stiffness matrix, and the nodal load matrix of system are the integration of their corresponding unit matrix and vector, shown in

$$
\begin{aligned}
\mathbf{M} & =\sum_{e} \mathbf{M}^{e}, \\
\mathbf{C} & =\sum_{e} \mathbf{C}^{e}, \\
\mathbf{K} & =\sum_{e} \mathbf{K}^{e}, \\
\mathbf{Q} & =\sum_{e} \mathbf{Q}^{e} .
\end{aligned}
$$

Due to the randomicity of $\delta \mathbf{U},(14)$ can be written:

$$
\mathbf{M U ̈}+\mathbf{C U}+\mathbf{K U}=\mathbf{Q} \text {. }
$$

2.1.2. The Calculation Method of Explicit Central Difference. The node displacement, velocity, and acceleration at time $0, t^{1}, t^{2}, \ldots, t^{n}$ are assumed to be known, and the structure response needs to be solved at time $t^{n+1}(t+\Delta t)$. The central difference expressions for velocity and acceleration at time $t$ are

$$
\begin{aligned}
& \ddot{\mathbf{U}}_{t}=\frac{1}{\Delta t^{2}}\left(\mathbf{U}_{t-\Delta t}-2 \mathbf{U}_{t}+\mathbf{U}_{t+\Delta t}\right), \\
& \dot{\mathbf{U}}_{t}=\frac{1}{\Delta t}\left(-\mathbf{U}_{t-\Delta t}+\mathbf{U}_{t+\Delta t}\right) .
\end{aligned}
$$

The displacement solution $\mathbf{U}_{t+\Delta t}$ at time $t+\Delta t$ is determined from the equation of motion at time $t$. Therefore, the recurrence formula of central difference method, (19), can be obtained by substituting (18) into (17).

$$
\begin{aligned}
\left(\frac{1}{\Delta t^{2}} \mathbf{M}+\frac{1}{2 \Delta t} \mathbf{C}\right) \mathbf{U}_{t+\Delta t} \\
=\mathbf{Q}_{t}-\left(\mathbf{K}-\frac{2}{\Delta t^{2}} \mathbf{M}\right) \mathbf{U}_{t} \\
\quad-\left(\frac{1}{\Delta t^{2}} \mathbf{M}-\frac{1}{2 \Delta t} \mathbf{C}\right) \mathbf{U}_{t-\Delta t} .
\end{aligned}
$$

If $\mathbf{U}_{t-\Delta t}$ and $\mathbf{U}_{t}$ are obtained, $\mathbf{U}_{t+\Delta t}$ can be obtained by (19). Substituting $\mathbf{U}_{t+\Delta t}$ back into the geometric equation and the physical equation, the element stress and strain at time $t+\Delta t$ can be solved. The recurrence (19) is used to solve the solution at each discrete time point without iterative solution; therefore it is called explicit algorithm and also called explicit step by step integration method.

Explicit central difference method is conditionally stable. When it is used to deal with the concrete problems, the time step $\Delta t$ must be shorter than a critical value $\Delta t_{\text {cr }}$ determined by the equation property of the problems. Otherwise, the explicit algorithm is unstable. Therefore the stability condition for the central difference method is to satisfy the following equation [32]:

$$
\Delta t \leq \Delta t_{\mathrm{cr}}=\frac{2}{\omega_{n}}=\frac{T_{n}}{\pi},
$$

where $\omega_{n}$ is the highest-order natural frequencies of system and $T_{n}$ is the minimum natural period of system.

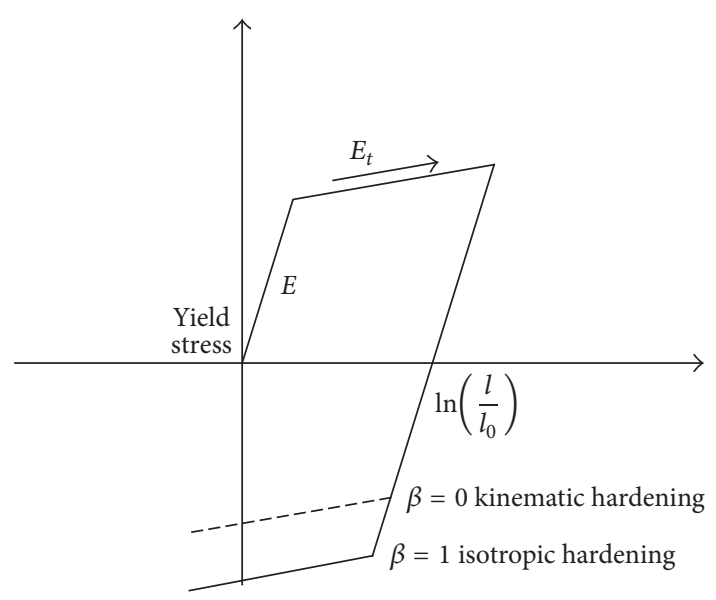

FIGURE 1: Elastic-plastic behavior of isotropic and kinematic hardening models.

\subsection{The Selection of Element Type and Material Model}

2.2.1. The Selection of Element Type. For the components of side piers, auxiliary piers, and main pylons, three element types (SOLID164, SOLID168, and BEAM161) can be selected. SOLID elements are usually used to simulate the local failure of components; meanwhile SOLID elements will consume a lot of computer memory with low efficiency. However, the purpose of this research is to obtain the whole failure and the concrete failure section of components. Therefore BEAM161 elements, including finite transverse shear strains, are available to be used. For the components of steel truss girder, two element types (LINK160 and BEAM161) can be selected. LINK160 elements can only bear axial load. Steel truss components need bearing both axial and moment load. So BEAM161 elements, consisting of the properties of compression and bending, are selected to simulate steel truss components. For the components of cables, there is only one element type (LINK167) which is used to simulate cables. LINK167 elements allow elastic cables to be realistically modeled. For the components of bearings among the pylons, the piers, and the steel truss girder, there is only one element type of COMBI165 which can be used to model simple spring bearing or damper system. For secondary dead load and the overburden load, they are realized by attached masses modeled by using the only mass element type of MASS166 which are defined by a single node with concentrated mass component.

2.2.2. The Material Models of Steel and Concrete. Isotropic and kinematic hardening or a combination of them may be obtained by varying a parameter, called $\beta$ between 0 and 1 . For $\beta$ equal to 0 and 1 , respectively, kinematic and isotropic hardening are obtained as shown in Figure 1 [33].

The kinematic hardening model is adopted to model the steel and concrete, and this model is appropriate to be applied in the collapse simulation of reinforced concrete bridges and steel bridges with the function of considering material failure. Meanwhile the material model is associated with strain rate. 


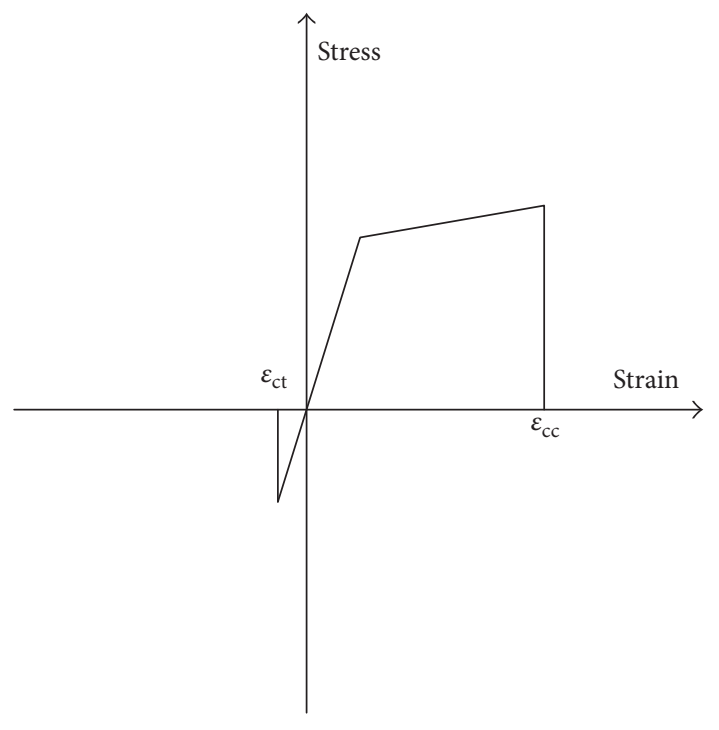

(a) Concrete material

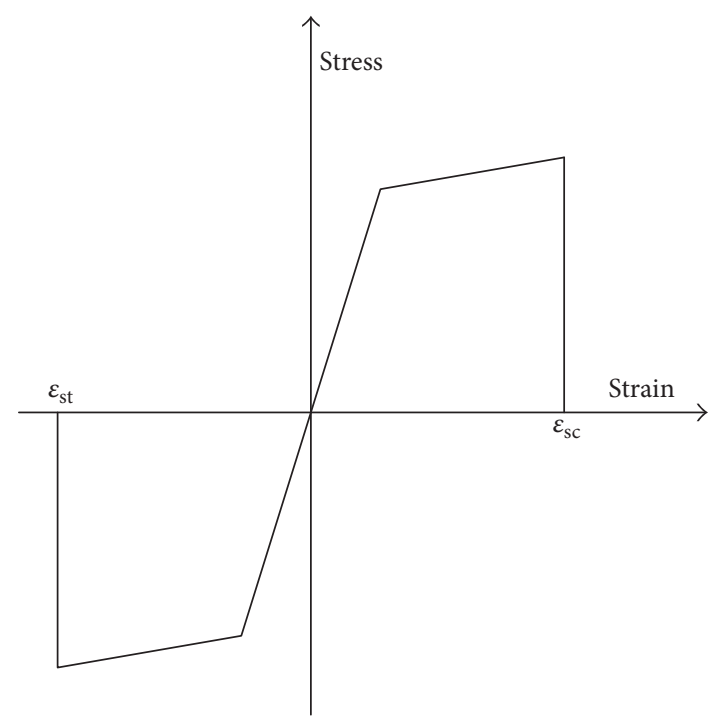

(b) Steel material

Figure 2: Material failure models of concrete and steel.

2.2.3. The Material Model of Cables. This material can be used only as a discrete beam element. The force, $F$, generated by the cable is nonzero only if the cable is in tension. The force is given by [33].

$$
F=K \cdot \max (\Delta L, 0),
$$

where $\Delta L$ is the change in length

$$
\Delta L=\text { current length }- \text { (initial length }- \text { offset }) .
$$

And the stiffness is defined as

$$
K=E \cdot \frac{\text { area }}{\text { (initial length }- \text { offset })} \text {. }
$$

The area and offset are defined on either the cross section or element cards in the LS-DYNA input. For a slack cable the offset should be input as a negative length. For an initial tensile force the offset should be positive. If a load curve is specified, Yong's modulus will be ignored and the load curve will be used instead. The points on the load curve are defined as engineering stress versus engineering strain, that is, the change in length over the initial length. The unloading behavior follows the loading.

2.2.4. The Material Model of Spring Bearing. The yield force is taken from the load curve [33].

$$
F^{Y}=F_{y}\left(\Delta L^{\text {plastic }}\right),
$$

where $L^{\text {plastic }}$ is the plastic deflection. A trial force is computed as

$$
F^{T}=F^{n}+K \cdot \Delta \dot{L} \cdot \Delta t
$$

And it is checked against the yield force to determine $F$ :

$$
F= \begin{cases}F^{Y}, & \text { if } F^{T}>F^{Y}, \\ F^{T}, & \text { if } F^{T} \leq F^{Y} .\end{cases}
$$

The final force, which includes rate effects and damping, is given by

$$
\begin{aligned}
& F^{n+1}=F \cdot\left[1+C_{1} \cdot \Delta \dot{L}+C_{2}\right. \\
& \left.\quad \cdot \operatorname{sgn}(\Delta \dot{L}) \ln \left(\max \left\{1, \frac{\Delta \dot{L}}{D L E}\right\}\right)\right]+D \Delta \dot{L} \\
& \quad+g(\Delta L) h(\Delta \dot{L}),
\end{aligned}
$$

where $C_{1}$ and $C_{2}$ are damping coefficients and DLE is a factor to scale time units.

Unless the origin of the curve starts at $(0,0)$, the negative part of the curve is used when the spring force is negative where the negative of the plastic displacement is used to interpolate $F_{y}$. The positive part of the curve is used whenever the force is positive. In these equations, $\Delta L$ is the change in length.

2.3. The Element Failure Criteria. In the paper, the failure elements are used to simulate the collapse failure of long-span cable-stayed bridges under strong seismic excitation. The stiffness and masses of the failure elements are multiplied by a very small reduction factor, resulting in the failure elements making no contribution to the structure and the external load acted on the failure elements being released. In fact, the failure elements still exist in the list of elements and remain unchanged without reassembling the whole stiffness matrix of structure. The failure criteria are defined in the material models, and the failure elements are no longer shown in the postprocessing; therefore the collapse failure of structure can be realized. The failure models of steel and concrete material are displayed in Figure 2.

The cables failure can not be defined in the cables material model by the software LS-DYNA; another method 


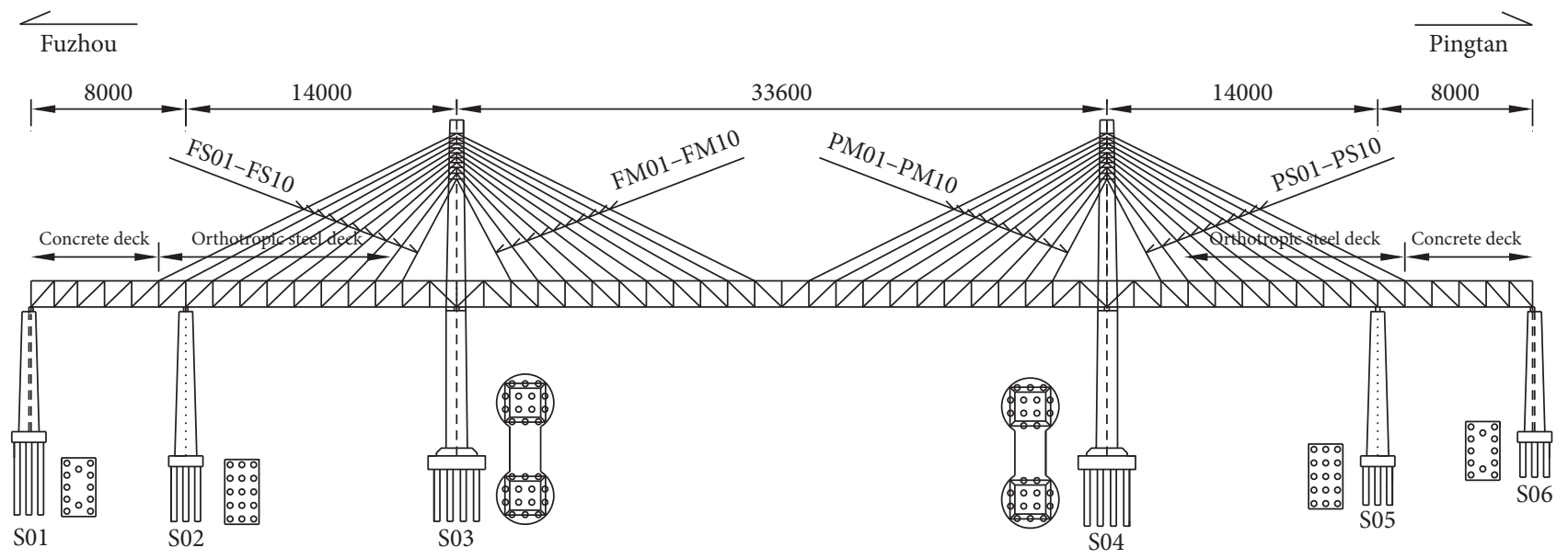

FIgURE 3: The elevation layout of Daxiao Liandao waterway bridge (unit: $\mathrm{cm}$ ).

put forward in the study is to establish the anchorage section between cables and truss girder by using BEAM161 element to simulate the cables failure. When the cable force reaches the limit value, the beam elements of the anchorage section cause failure that resulting in the cables out of work.

The bearings among the piers, pylons, and truss girder are modeled by the spring element COMBI165 which can simulate bearing failure. The sliding bearing failure is defined in the spring material model by setting the displacement limit value which is the maximum sliding displacement of sliding bearing. The fixed bearing failure is defined in the spring material model by setting the yield force which is the maximum bearing capacity of the fixed bearing.

\section{The Finite Element Model of Cable-Stayed Bridge}

3.1. Engineering Background. Daxiao Liandao waterway bridge, which is the steel truss cable-stayed bridge with the span arrangement $(80+140+336+140+80) \mathrm{m}$, is a control engineering located between Fuzhou and Pingtan. The main girder of the cable-stayed bridge is the plate and truss composite steel truss girder structure provided with a secondary truss and is arranged into double decks. The upper deck of the bridge carries 6-lane expressway while the lower deck carries 2-track railway. The main bridge is located between S01 pier and S06 pier; the elevation arrangement of Daxiao Liandao waterway bridge and the cross section of the girder are shown in Figures 3 and 4.

\subsection{The Explicit Dynamic Finite Element Model}

3.2.1. Parameters of Material Models and Definition of Failure Criteria. C50 high performance concrete is used in the main pylons with the compressive strength $f_{c}=33.5 \mathrm{MPa}$, the tensile strength $f_{\text {ct }}=3.1 \mathrm{MPa}$, the elasticity modulus $E_{c}=$ $3.55 e 4 \mathrm{MPa}$, and the yield strength is $55 \mathrm{MPa}$; C50 concrete is used in the piers with the compressive strength $f_{c}=$ 32.4 MPa, the tensile strength $f_{\mathrm{ct}}=2.65 \mathrm{MPa}$, the elasticity

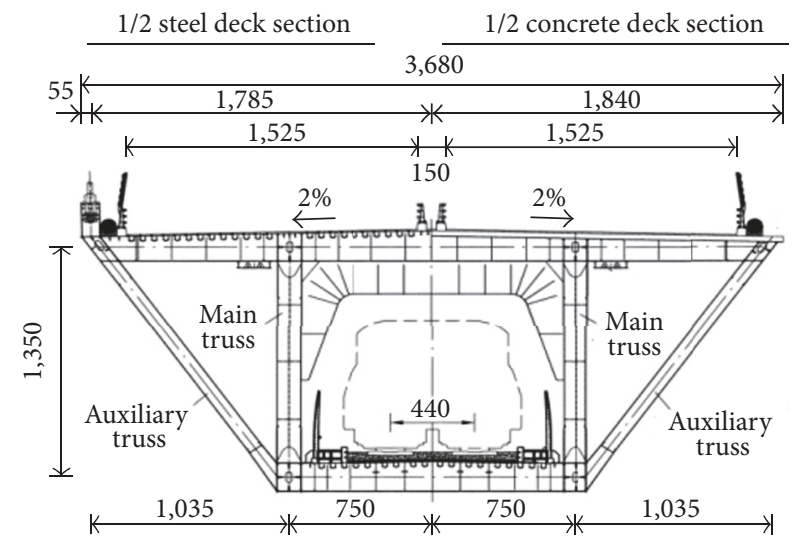

FIgURE 4: The girder cross section of Daxiao Liandao waterway bridge (unit: $\mathrm{cm}$ ).

modulus $E_{c}=3.45 e 4 \mathrm{MPa}$, and the yield strength is $50 \mathrm{MPa}$; C40 concrete is used in the pile caps and piles with the compressive strength $f_{c}=26.8 \mathrm{MPa}$, the tensile strength $f_{\text {ct }}=2.4 \mathrm{MPa}$, the elasticity modulus $E_{c}=3.25 e 4 \mathrm{MPa}$, and the yield strength is $40 \mathrm{MPa}$; $370 \mathrm{qD}$ steel is used in the truss girder with the compressive strength $f_{s}=295 \mathrm{MPa}$, the tensile strength $f_{\text {st }}=295 \mathrm{MPa}$, the elasticity modulus $E_{s}=2.1 e 5 \mathrm{MPa}$, and the yield strength is $370 \mathrm{MPa}$; the failure strain of concrete is 0.004 [34], the failure strain of steel is 0.2 [34], and the tangent modulus $E^{t}=0.01 E$ [22]. The parameters of concrete and steel material model (MAT_PLASTIC_KINEMATIC) are shown in Tables 1 and 2 , respectively.

The spring material model (MAT_INELASTIC_SPRING_ DISCRETE_BEAM) can be used to simulate the stiffness of bearings in the three translational directions and the failure state of the bearings by setting the corresponding stiffness parameters and the failure criteria including yield force and yield displacement, respectively. The stiffness of bearings in 
TABLE 1: The parameters of concrete material model.

\begin{tabular}{lcccccccccc}
\hline MID & RO & E & PR & SIGY & ETAN & BETA & SRC & SRP & FS & VP \\
\hline C50 HI & 2625 & $3.55 e 10$ & 0.17 & $50 e 6$ & $3.55 e 08$ & 0 & 99.3 & 1.93 & 0.004 & 0 \\
C50 & 2625 & $3.45 e 10$ & 0.2 & $50 e 6$ & $3.45 e 08$ & 0 & 99.3 & 1.93 & 0.004 & 0 \\
C40 & 2625 & $3.25 e 10$ & 0.2 & $40 e 6$ & $3.25 e 08$ & 0 & 99.3 & 1.93 & 0.004 & 0 \\
\hline
\end{tabular}

TABLE 2: The parameters of steel material model.

\begin{tabular}{ccccccccccc}
\hline MID & RO & E & PR & SIGY & ETAN & BETA & SRC & SRP & FS & VP \\
\hline Q370 & 7820 & $2.1 e 11$ & 0.3 & $370 e 6$ & $2.1 e 9$ & 0 & 40.0 & 5.0 & 0.2 & 0 \\
\hline
\end{tabular}

TABLE 3: Support reaction $R$ of S01 S06 piers bearings.

\begin{tabular}{|c|c|c|c|c|c|c|}
\hline Bearing location & S01 & S02 & S03 & S04 & S05 & S06 \\
\hline Support reaction $R(\mathrm{~N})$ & $8.5 e 6$ & $1.25 e 7$ & $1.25 e 7$ & $1.25 e 7$ & $1.25 e 7$ & $8.5 e 6$ \\
\hline
\end{tabular}

the vertical direction is defined as infinity and the stiffness of bearings in the horizontal direction can be calculated by [35]

$$
K=\frac{F_{\max }}{x_{y}}
$$

where $K$ is the stiffness of bearings $(\mathrm{N} / \mathrm{m})$, for the horizontal sliding bearings $F_{\max }$ equals $\mu_{d} R$, in which $\mu_{d}$ is the friction coefficient with the value of 0.02 and $R$ is the support reaction $(\mathrm{N})$, for the horizontal fixed bearings $F_{\max }$ equals $20 \%$ of the bearing capacity of bearings in the vertical direction, and $x_{y}$ is the failure displacement of bearings with the value of $0.002 \mathrm{~m}$.

The failure criteria of bearings in the vertical direction are defined by failure force which is the vertical bearing capacity of bearings. The failure criteria of fixed bearings in the horizontal direction are defined by the failure force which is $20 \%$ of the vertical capacity of bearings. The failure criteria of sliding bearings in the horizontal direction are defined by the failure force and failure displacement together. The failure force, which is the maximum horizontal friction force $F_{\max }$, is used to judge when the sliding bearings start to slid (when the failure force reaches the maximum horizontal friction force $F_{\text {max }}$, the sliding bearing starts to slid). After the sliding bearings start to slid, the failure displacement, which is defined by the maximum horizontal displacement with the value of $\pm 200 \mathrm{~mm}$ in the longitudinal direction and the value of $\pm 50 \mathrm{~mm}$ in the transversal direction, is used to judge when the sliding bearings cause failure.

The support reaction $R$ of S01 S06 pier bearings is shown in Table 3.

3.2.2. Boundary Conditions. The bottom of S01 S06 piers is fixed in all the degree of freedom. One longitudinal sliding bearing and one multidirectional sliding bearing are set up between S01/S02/S04/S05/S06 pier and girder, respectively. One fixed bearing and one transversal sliding bearing are set up between S03 main pylon and girder. The bearings' arrangement is shown in Figure 5.

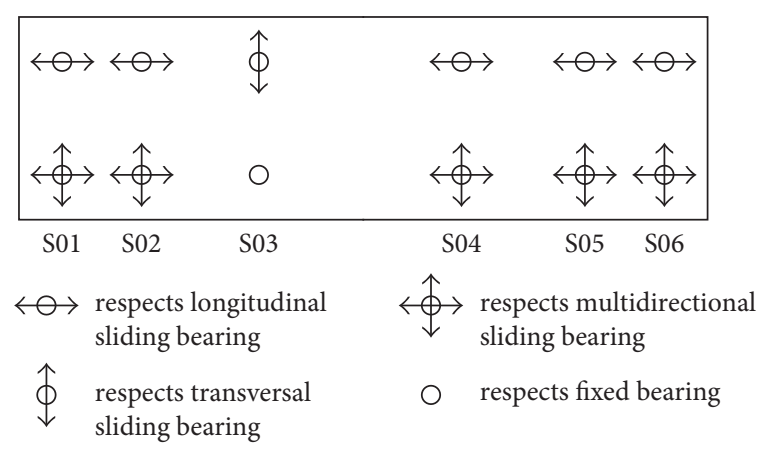

FIGURE 5: Bearing arrangement.

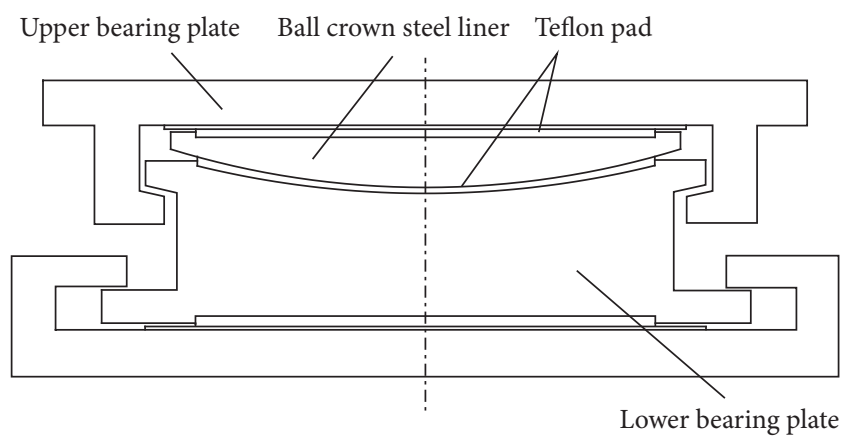

FIGURE 6: Bearing structure diagram.

Spherical steel bearings, consisting of upper bearing plate, lower bearing plate, and ball crown steel liner, are used in this cable-stayed bridge. The structure diagram of bearings is shown in Figure 6. The bearing type of QZ12500 is adopted in the bearings between side piers (S01/S06) and main girder, and QZ20000 is used in other bearings. QZ represents bearing type and 12500 (20000) represents the vertical capacity of bearings whose unit is $\mathrm{kN}$. The bearing friction coefficient 
TABLE 4: Natural frequencies and modal characteristics.

\begin{tabular}{lccc}
\hline Order number & Period & Frequency & Modal characteristics \\
\hline 1 & 3.382 & 0.29569 & Longitudinal floating vibration \\
2 & 2.557 & 0.39102 & Lateral bending vibration \\
3 & 2.421 & 0.41310 & Antisymmetric lateral bending vibration \\
4 & 2.157 & 0.46364 & Vertical bending vibration \\
5 & 1.991 & 0.50236 & Lateral bending vibration \\
6 & 1.310 & 0.76341 & Longitudinal bending vibration of auxiliary pier \\
7 & 1.276 & 0.78358 & Antisymmetric vertical bending vibration \\
8 & 1.231 & 0.81228 & Antisymmetric lateral bending vibration \\
9 & 1.223 & 0.81749 & Lateral bending-torsional coupling vibration \\
10 & 1.060 & 0.94335 & Torsional vibration \\
\hline
\end{tabular}

TABLE 5: Recorded parameters of seismic waves.

\begin{tabular}{|c|c|c|c|c|c|c|}
\hline Number & Earthquake name & Station name & Record component & $\begin{array}{l}\text { Magnitude } \\
(\mathrm{Ms})\end{array}$ & $\begin{array}{l}\text { Vs30 } \\
(\mathrm{m} / \mathrm{s})\end{array}$ & $\begin{array}{c}\text { PGA } \\
(\mathrm{g})\end{array}$ \\
\hline RSN6-H1 & Imperial Valley-02 & El Centro Array \#9 & ELC180 & 6.95 & 213.4 & 0.281 \\
\hline RSN6-H2 & Imperial Valley-02 & El Centro Array \#9 & ELC270 & 6.95 & 213.4 & 0.211 \\
\hline RSN13-H1 & Kern County & Pasaden-CIT Athenaeum & PAS180 & 7.36 & 415.1 & 0.048 \\
\hline
\end{tabular}

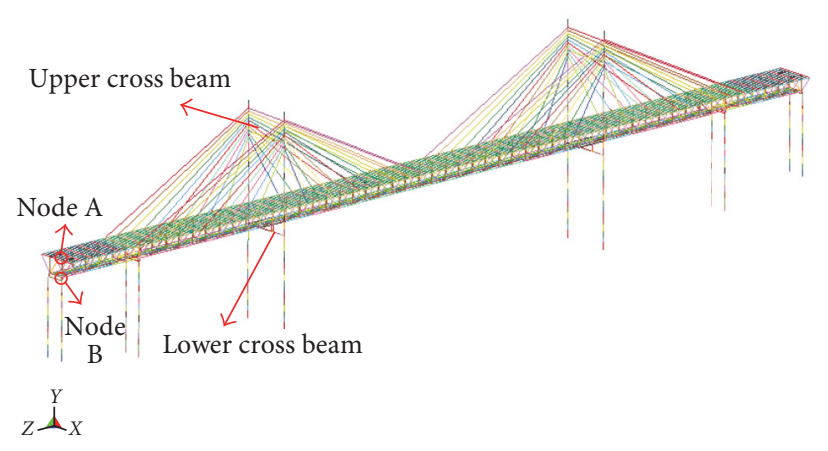

FIGURE 7: Finite element model.

is 0.02 , the horizontal capacity of bearings is $20 \%$ of the bearings' vertical capacity, the maximum bearing rotation is $0.03 \mathrm{rad}$, the maximum horizontal displacement in the longitudinal direction is $\pm 200 \mathrm{~mm}$, and the maximum horizontal displacement in the transversal direction is $\pm 50 \mathrm{~mm}$.

\subsubsection{The Finite Element Model and Dynamic Characteristics.} The explicit FE model of Daxiao Liandao cable-stayed bridge was established to simulate its whole collapse failure process with 6838 elements and 8120 nodes. The explicit FE model of the cable-stayed bridge is shown in Figure 7.

It can be obtained from the modal analysis that the first natural frequency value is 0.29596 and the corresponding period value is $3.382 \mathrm{~s}$. The first mode is longitudinal floating vibration, and the second mode is lateral bending vibration. It can be found from the first ten modes that the symmetric (antisymmetric) vertical bending vibration and symmetric (antisymmetric) lateral bending vibration are the main vibration modes. The first ten natural frequencies, periods, and modal characteristics are listed in Table 4.

3.3. Seismic Ground Motions. Daxiao Liandao waterway cable-stayed bridge is located between Changle city and Pingtan country with the bridge site classification of II, seismic precautionary intensity of 7 grade, and the design basic acceleration of $0.1 \mathrm{~g}$. Three seismic waves are selected according to the basic principle catering to the site classification and the recorded parameters of the three seismic waves are shown in Table 5.

The selected seismic waves can not satisfy the requirement of the collapse failure analysis of cable-stayed bridge under strong seismic excitations, because the peak ground acceleration of the three selected seismic waves is not large enough. Therefore the three seismic waves are needed to be amplified with the peak ground acceleration reaching $1 \mathrm{~g}$. Meanwhile in order to save calculation time and improve work efficiency a section of the recorded seismic waves including the peak ground acceleration is intercepted with the duration time of $20 \mathrm{~s}$. The time-history curves of recorded seismic waves are shown in Figure 8.

\section{The Collapse Failure Process and Failure Mechanisms}

\subsection{The Analysis Results under RSN6-H1 Seismic Wave}

4.1.1. Collapse Process Analysis of Cable-Stayed Bridge. The amplified RSN6-H1 seismic wave was applied to the finite element model of Daxiao Liandao cable-stayed bridge to simulate the whole process in which the structure began 


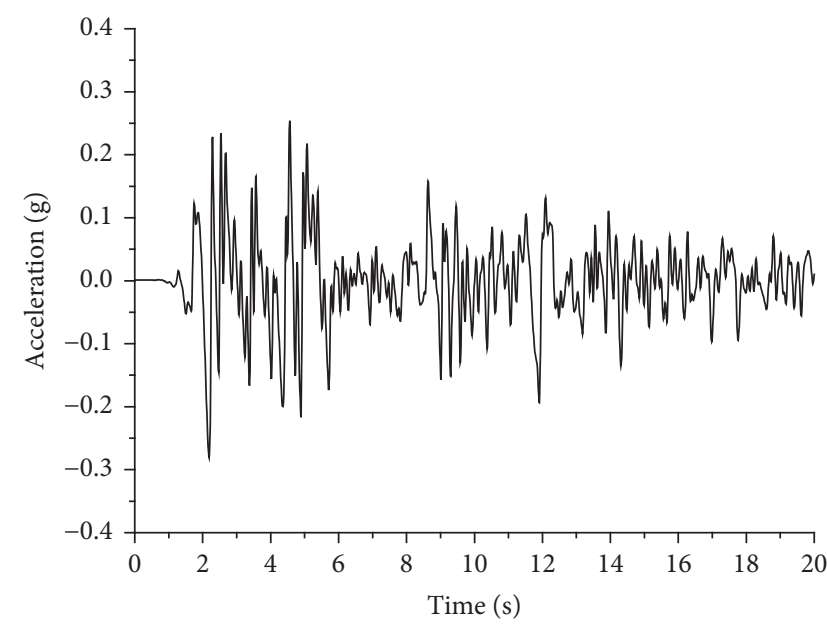

RSN6-H1 seismic wave

(a) RSN6-H1 seismic wave

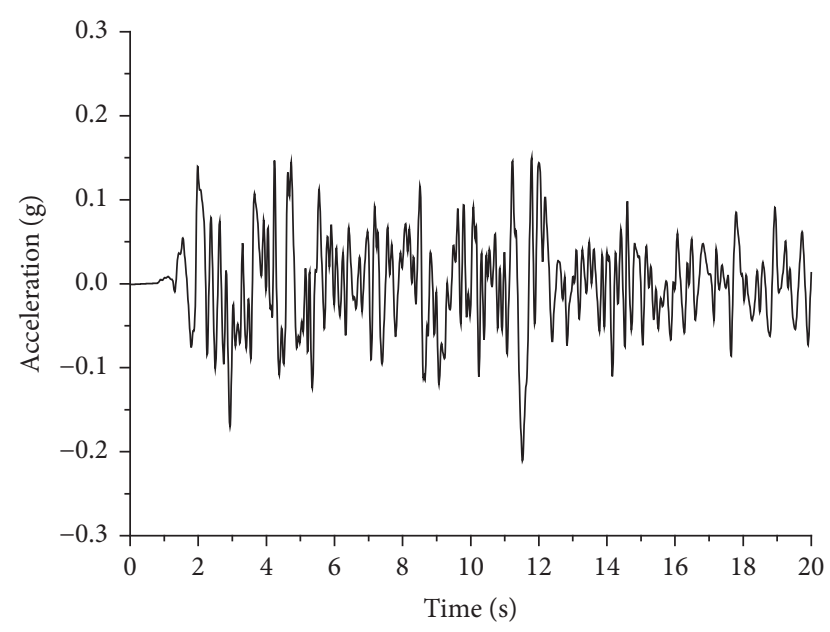

RSN6-H2 seismic wave

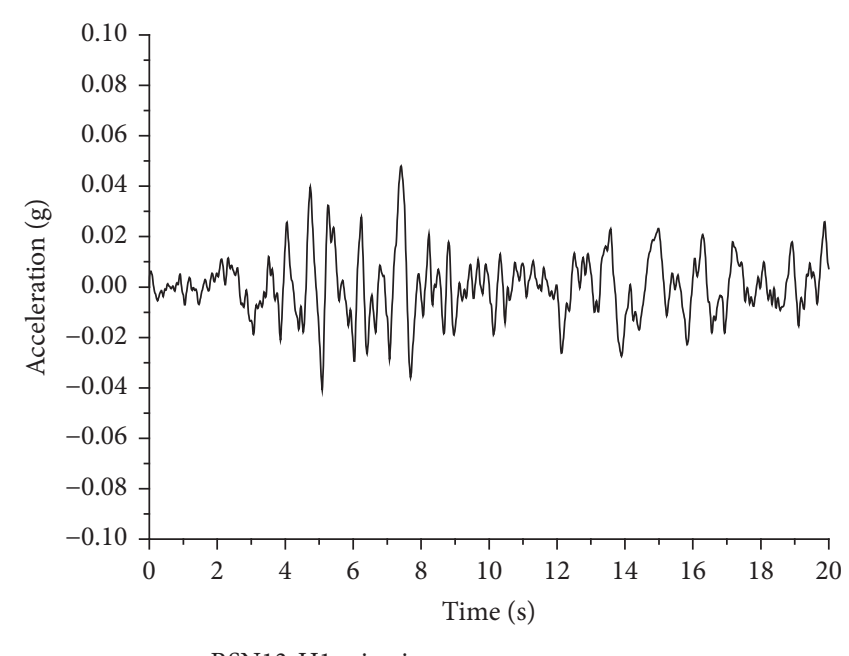

(c) RSN13-H1 seismic wave

FIgURE 8: The time-history curves of recorded seismic waves.

to damage gradually and eventually the collapse failure was observed. The whole collapse process is shown in Figure 9.

It can be obtained from the dynamic collapse process and the analysis results that all components of the cable-stayed bridge are within linear elastic conditions before $1 \mathrm{~s}$ and the whole structure is in well condition (Figure 9(a)) because of the smaller peak ground motion at begin of the seismic wave. With the continuously input of ground motion energy as well as the steady accumulation of structural damage, the first failure element occurs at the bottom of S02 auxiliary pier at time $4.06 \mathrm{~s}$ and the bottom elements of S02/S05 auxiliary pier step into completely yielding state at time $4.36 \mathrm{~s}$ (Figure 9(b)). The damage keeps on developing after the failure of auxiliary piers under seismic excitation, and the auxiliary pier bearings come into failure situation which is evident at time $5.48 \mathrm{~s}$ (Figure 9(c)). Further destruction of cable-stayed bridge leads to S01/S06 side pier bottom elements beginning to yield at time $8.5 \mathrm{~s}$, and the side pier bearings cause failure because of the excessive longitudinal displacement which reaches the maximum bearing displacement limit (Figure 9(d)). At time $12.64 \mathrm{~s}$, side piers are completely destroyed, the connection part between S03/S04 main pylon and lower cross beam begins to damage, and the cables do not show fracture damage (Figure 9(e)). At time $14.42 \mathrm{~s}$, the connection part between main pylon and lower cross beam completely yields resulting in the collapse of the main pylon, and the end cables show fracture damage (Figure 9(f)). It can be noted that the main failure mode of the cable-stayed bridge subjected to longitudinal seismic wave includes the plastic damage at the bottom of auxiliary piers, side piers, and main pylons, at the connection part between main pylon and lower cross beam and at the anchorage section of end cables and the large deformation in the longitudinal direction.

4.1.2. Moment Time-History Analysis of Pylon Elements. It can be found from the moment time-history results of main pylon elements in different positions that the elements failure occurs in the bottom position of the main pylons, in the lower 


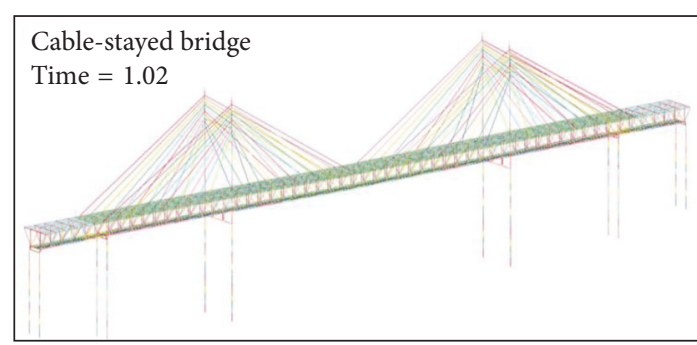

(a) Structure state at $1.02 \mathrm{~s}$

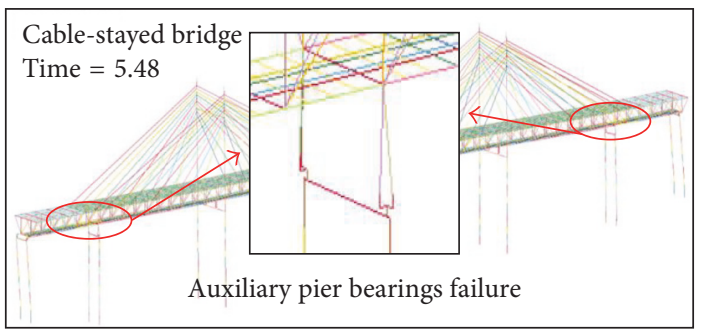

(c) Structure state at $5.48 \mathrm{~s}$

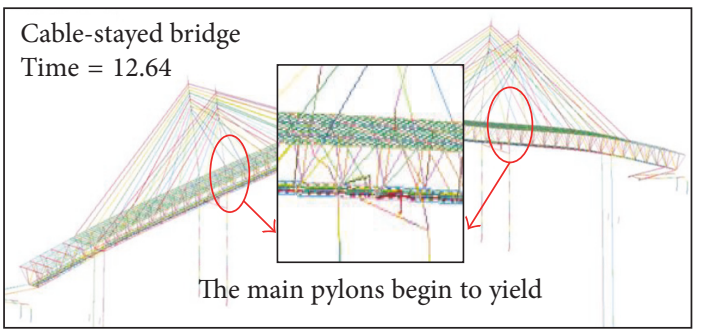

(e) Structure state at $12.64 \mathrm{~s}$

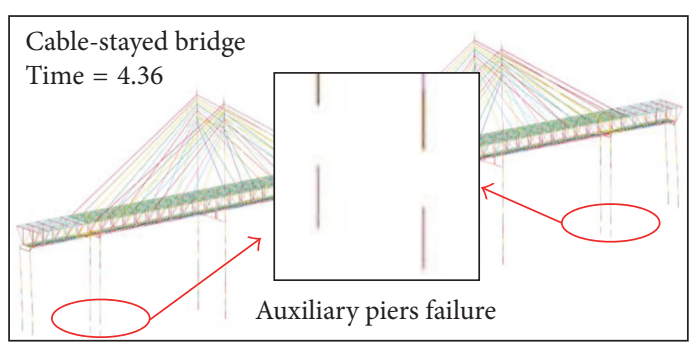

(b) Structure state at $4.36 \mathrm{~s}$

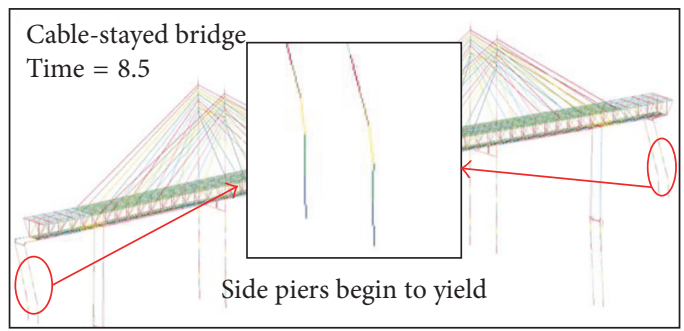

(d) Structure state at $8.5 \mathrm{~s}$

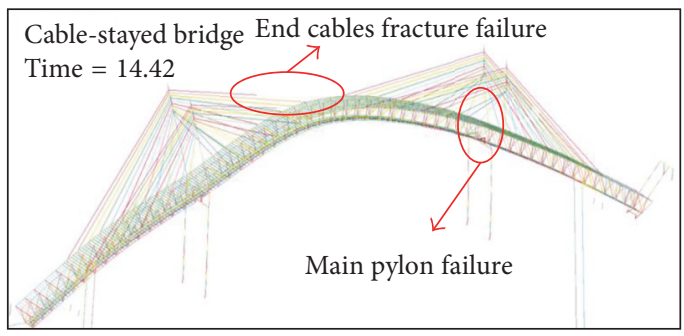

(f) Structure state at $14.42 \mathrm{~s}$

FIGURE 9: Collapse failure process under RSN6-H1 seismic wave.

cross beam position of the main pylons and in the upper cross beam position of the main pylons. Figures $10(\mathrm{a})-10(\mathrm{c})$ present the moment time-history curves of the elements in the three positions mentioned above, respectively. As shown in the figures, the elements moment will reduce to be zero at a specific time that indicates the completely failure happens to the elements. It can be concluded from the elements failure time in the three positions that the elements failure is in a specific sequence beginning from the main pylon element in the lower cross beam position to the main pylon element in the bottom position and finally to the main pylon element in the upper cross beam position.

\subsubsection{Axial Force Time-History Analysis of Cable Elements.} Figures 10(d)-10(f) show the axial force time-history curves of FS01/FS05/FS10 cable elements, respectively. The number order of cable elements is $01,02, \ldots, 10$ from the near side of S03/S04 pylon to the far side of S03/S04 pylon, respectively (see Figure 3). The letters (FS/FM/PS/PM) before the numbers denote different side cables of the main pylons. Therefore FS01/FM01/PS01/PM01 cable is near the pylons and FS10/FM10/PS10/PM10 cable is far from the pylons. It can be seen from the axial force time-history curves of FS01 and FS05 cable elements that the axial force fluctuates within a certain range before the whole collapse of the cable-stayed bridge structure (Figures 10(d) and 10(e)). Although there are obvious changes in axial force, the axial force does not exceed the ultimate bearing capacity of cables. It can be obtained from the axial force time-history curve of FS10 cable element that the cable element axial force show larger fluctuation before the collapse of cable-stayed bridge and constantly increases until to cable fracture failure (Figure 10(f)). The same axial force changes law is obtained for the other side cables (FM01, FM02,..., FM10) of S03 pylon. The further analysis of the cable-stayed bridge structure system can lead to the reasons for the cable axial force change law. Because of the failure of auxiliary piers and side piers, the vertical support at both ends of the girder is lost making the load born by auxiliary piers and side piers transfer to the end cables and resulting in the larger axial force fluctuation of the end cables. However the axial force fluctuation of the cables near S03 pylon is influenced slightly. Only several end cables show fracture failure in the collapse process of the whole structure system, so the cables fracture failure is not the main reason for the whole collapse of cable-stayed bridge structure.

4.1.4. Displacement Analysis of Girder Elements. Figures 11(a) and 11(b) represent the longitudinal displacement timehistory curve of node $\mathrm{A}$ and node $\mathrm{B}$ and the vertical displacement time-history curve of node $\mathrm{A}$ and node $\mathrm{B}$, 


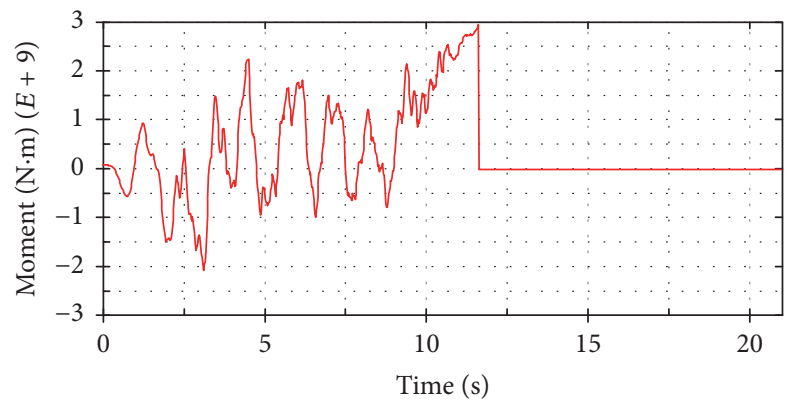

(a) The moment time-history curve of the pylon element in the lower cross beam position

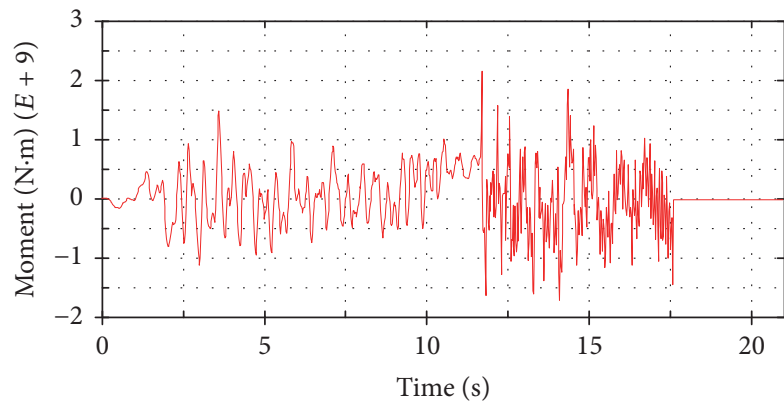

(c) The moment time-history curve of the pylon element in the upper cross beam position

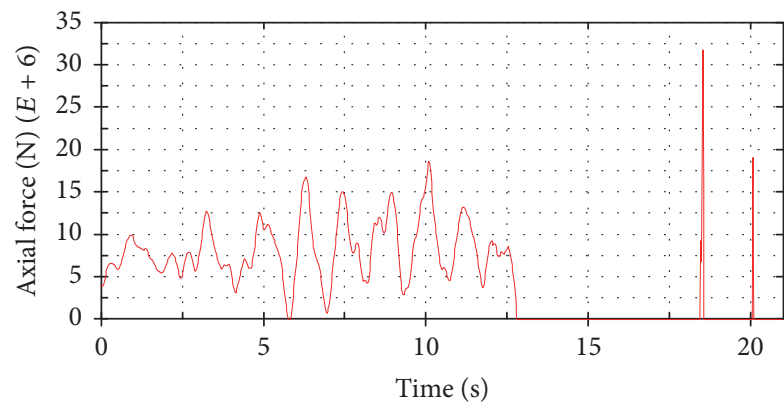

(e) The axial force time-history curve of FS05 cable element

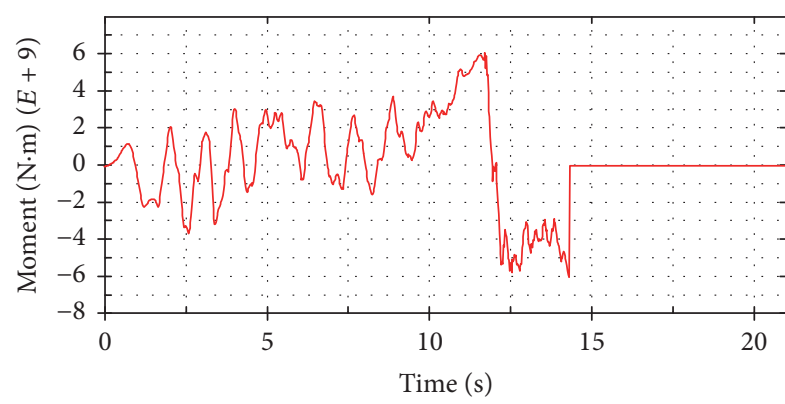

(b) The moment time-history curve of the pylon bottom element

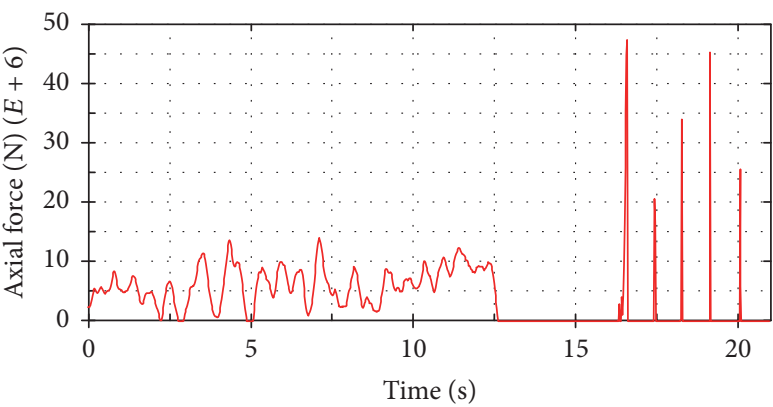

(d) The axial force time-history curve of FS01 cable element

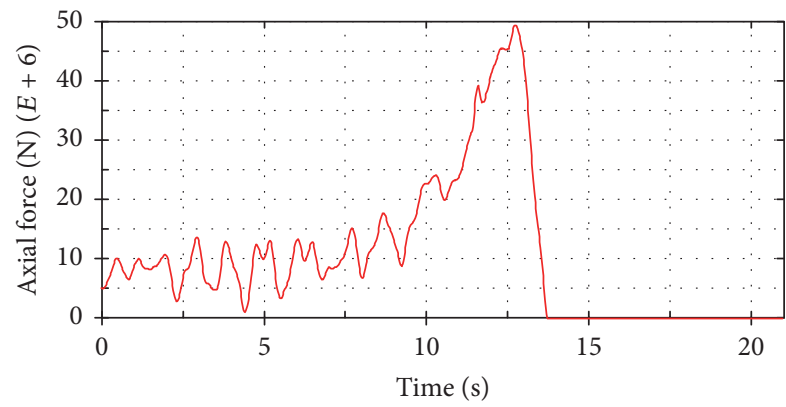

(f) The axial force time-history curve of FS10 cable element

FIGURE 10: Time-history curves of moment and axial force for elements.

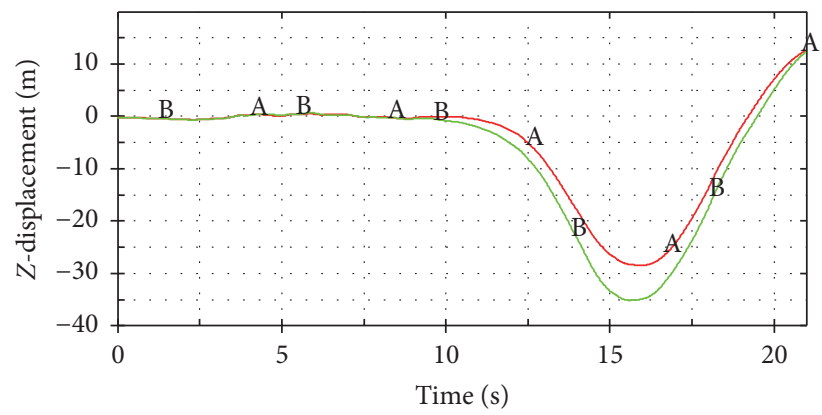

Node number

A. 5985

B 3034

(a) Time-history curves of longitudinal displacement

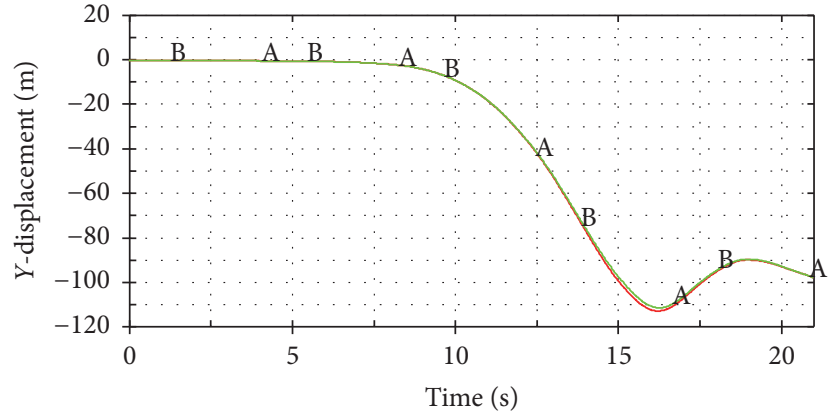

Node number

A. 5985

B 3034

(b) Time-history curves of vertical displacement

FIGURE 11: The displacement time-history curves of A and B nodes of girder deck. 


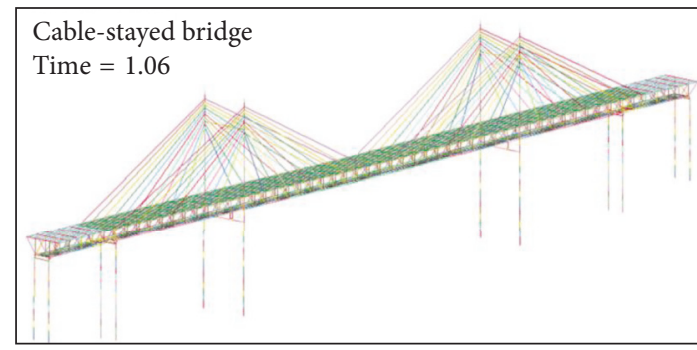

(a) Structure state at $1.06 \mathrm{~s}$

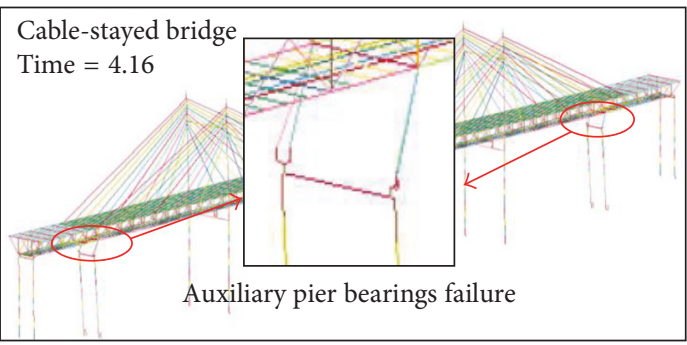

(c) Structure state at $4.16 \mathrm{~s}$

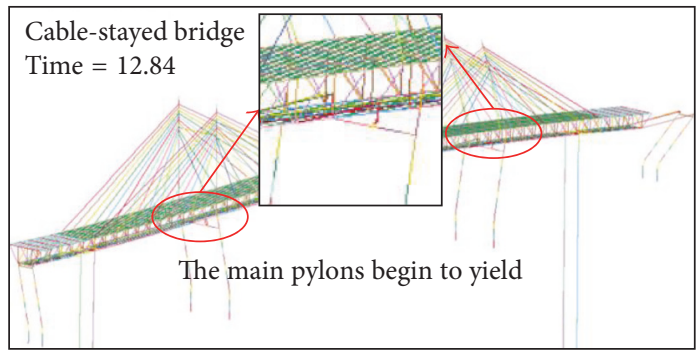

(e) Structure state at $12.84 \mathrm{~s}$

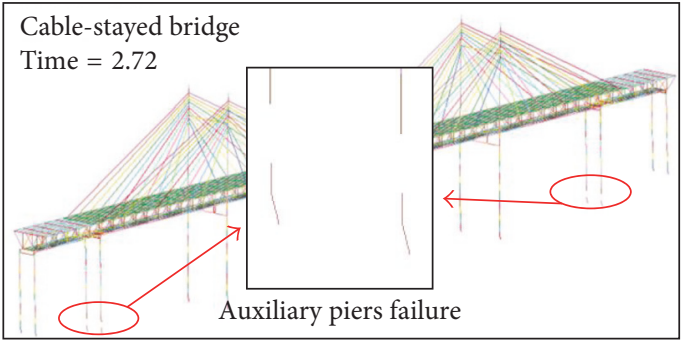

(b) Structure state at $2.72 \mathrm{~s}$

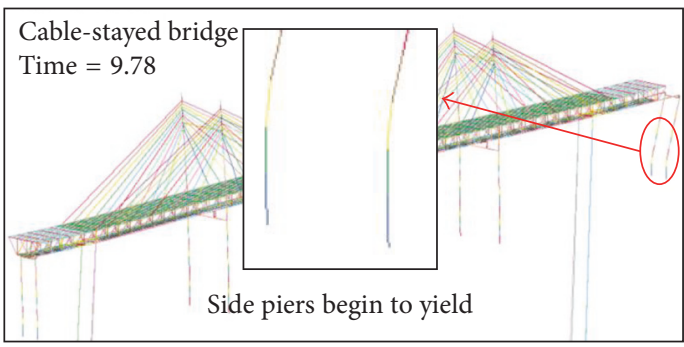

(d) Structure state at $9.78 \mathrm{~s}$

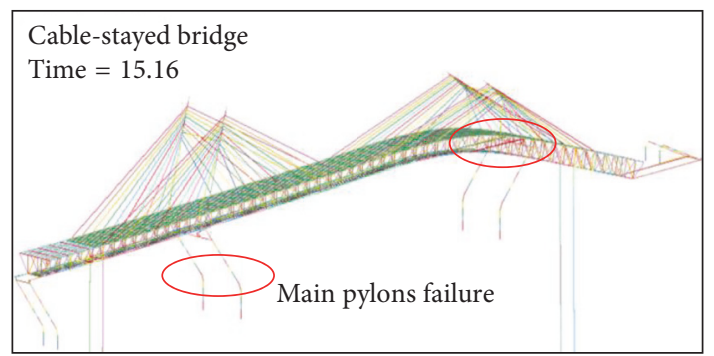

(f) Structure state at $15.16 \mathrm{~s}$

Figure 12: Collapse failure process under RSN6-H2 seismic wave.

respectively. Node A and node B are shown in Figure 7. As shown in Figure 11, the longitudinal displacement and the vertical displacement of node $A$ and node $B$ fluctuate within a certain displacement range before about $10 \mathrm{~s}$ that indicates the whole structural system do not cause serious damage. After the time of $10 \mathrm{~s}$, the longitudinal displacement and the vertical displacement all increase gradually and cause large displacement that indicates that the whole structural system causes serious damage, or even collapse.

\subsection{The Analysis Results under RSN6-H2 Seismic Wave}

4.2.1. Collapse Process Analysis of Cable-Stayed Bridge. The amplified RSN6-H2 seismic wave was applied to the finite element model of Daxiao Liandao cable-stayed bridge to simulate the whole process in which the structure began to damage to rose steadiness and eventually the collapse failure was observed. The whole collapse process is shown in Figure 12.

It can be obtained from the dynamic collapse process and the analysis results that all components of the cable-stayed bridge are within linear elastic conditions before $1 \mathrm{~s}$ and the whole structure is in well condition (Figure 12(a)) because of the smaller peak ground motion at begin of the seismic wave. With the continuously input of ground motion energy as well as the steady accumulation of structural damage, the first failure element occurs at the bottom of S02 auxiliary pier at time $2.62 \mathrm{~s}$ and the bottom elements of S02/S05 auxiliary pier step into completely yielding state at time $2.72 \mathrm{~s}$ (Figure 12(b)). The damage keeps on developing after the failure of auxiliary piers under seismic excitation, and the auxiliary pier bearings come into failure state which is evident at time $4.16 \mathrm{~s}$ (Figure 12(c)). Further destruction of cablestayed bridge leads to S01/S06 side pier bottom elements beginning to yield at time $9.78 \mathrm{~s}$, and the side pier bearings cause failure because of the excessive longitudinal displacement which reaches the maximum bearing displacement limit (Figure 12(d)). At time $12.84 \mathrm{~s}$, side piers are almost completely destroyed, the connection part between S03/S04 main pylon and lower cross beam begins to damage, and the cables do not show fracture damage (Figure 12(e)). At time $15.16 \mathrm{~s}$, the connection parts between S03/S04 main pylon and lower cross beam and the main pylon bottom completely yield resulting in the collapse of the main pylon, and the cables do not show fracture failure (Figure 12(f)). It can be noted that the main failure mode of the cable-stayed bridge subjected to longitudinal seismic wave includes the plastic damage at the bottom of auxiliary piers, side piers, and main pylons and 


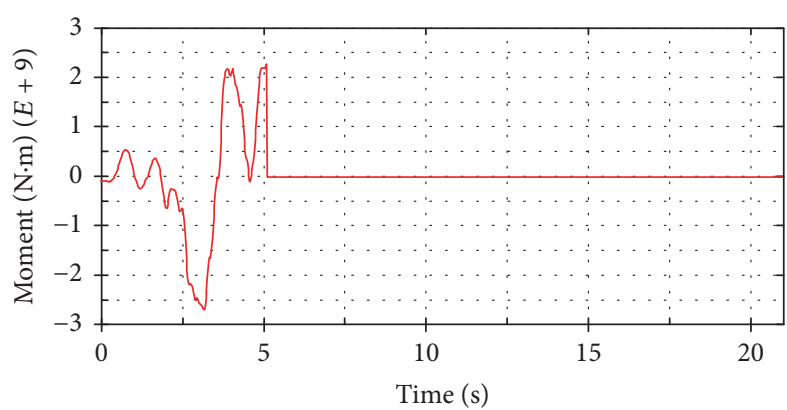

(a) The moment time-history curve of the pylon element in the lower cross beam position

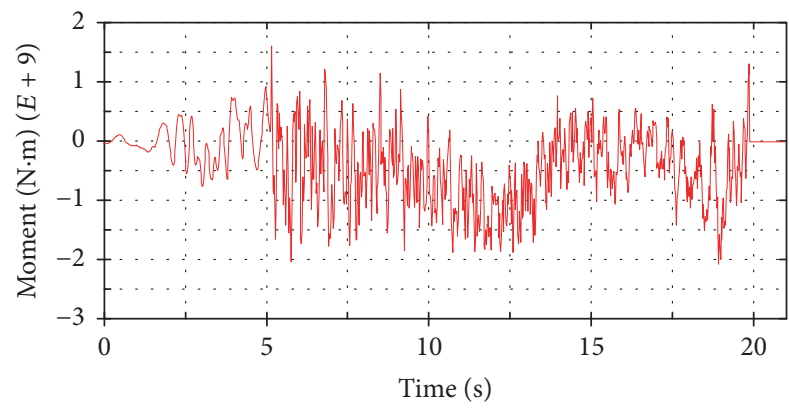

(c) The moment time-history curve of the pylon element in the upper cross beam position

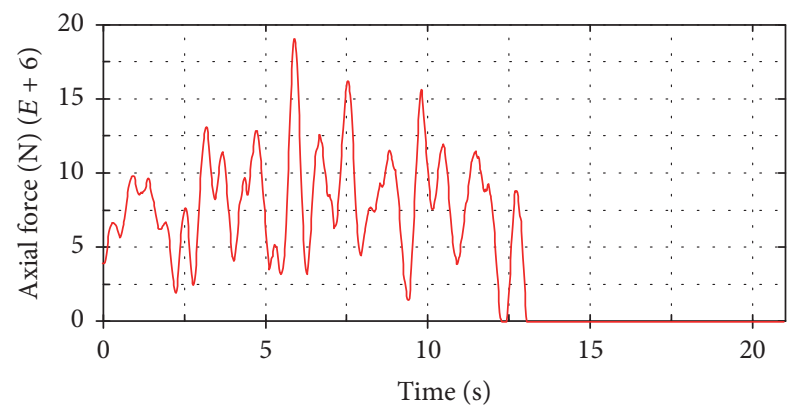

(e) The axial force time-history curve of FS05 cable element

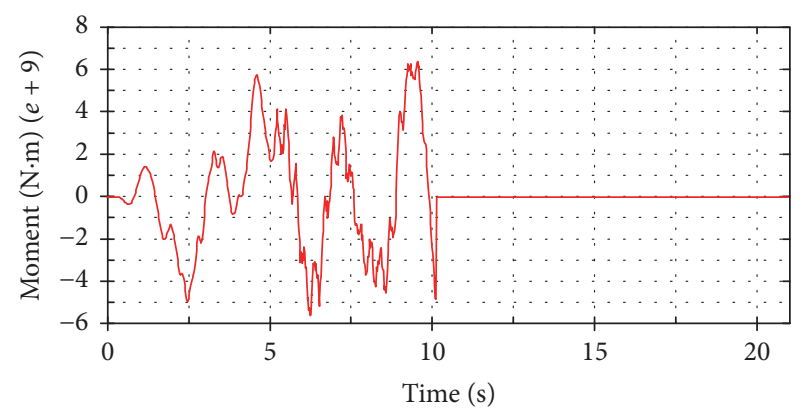

(b) The moment time-history curve of the pylon bottom element

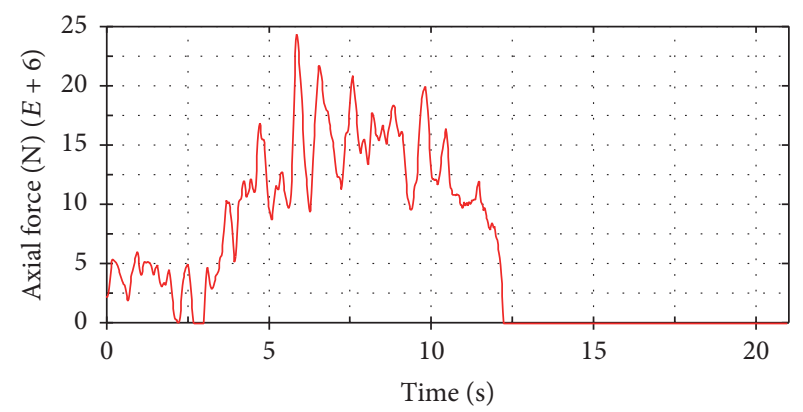

(d) The axial force time-history curve of FS01 cable element

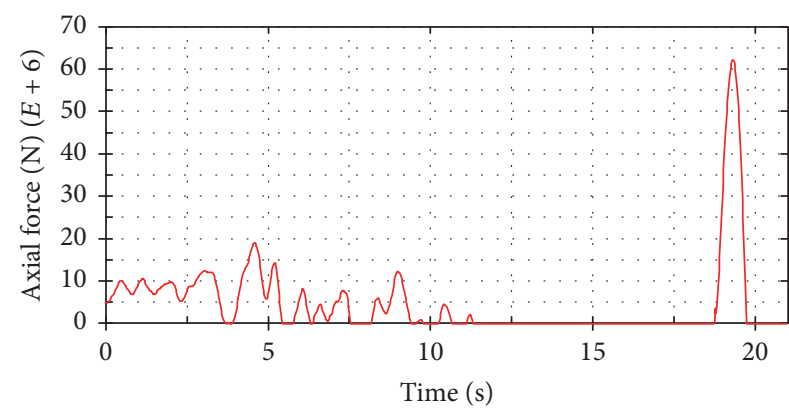

(f) The axial force time-history curve of FS10 cable element

FIGURE 13: Time-history curves of moment and axial force for elements.

at the connection part between main pylon and lower cross beam and the large deformation in the longitudinal direction.

4.2.2. Moment Time-History Analysis of Pylon Elements. It can be found from the moment time-history results of main pylon elements in different positions that the elements failure occurs in the bottom position of the main pylons, in the lower cross beam position of the main pylons, and in the upper cross beam position of the main pylons. Figures 13(a)-13(c) present the moment time-history curves of the elements in the three positions mentioned above, respectively. As shown in the figures, the elements moment will reduce to be zero at a specific time that indicates the completely failure happens to the elements. It can be concluded from the elements failure time in the three positions that the elements failure is in a specific sequence beginning from the main pylon element in the lower cross beam position to the main pylon element in the bottom position and finally to the main pylon element in the upper cross beam position.

\subsubsection{Axial Force Time-History Analysis of Cable Elements.} Figures 13(d)-13(f) show the axial force time-history curves of FS01/FS05/FS10 cable elements, respectively. It can be seen from the axial force time-history curves of FS01, FS05, and FS10 cable elements that the axial force fluctuates within a certain range before the whole collapse of the cable-stayed bridge structure. Although there are obvious changes in axial force, the axial force does not exceed the ultimate bearing capacity of all the cables. It can also be known that the axial force fluctuation range of FS01 cable element is the biggest of all, followed by that of FS05 cable element and of FS10 cable element in turn. However the change law of the axial force fluctuation of the other side cables (FM01, FM02, .., FM10) of S03 pylon is inverse. That is to say, the axial force fluctuation range of FM10 cable element 


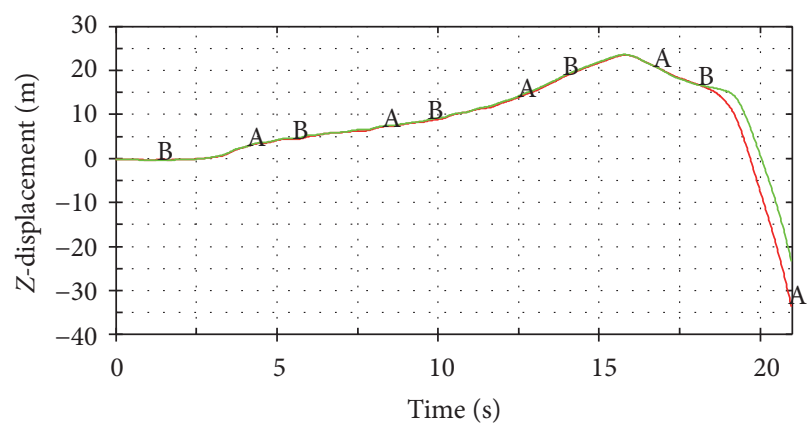

Node number

A. 5985

B 3034

(a) Time-history curves of longitudinal displacement

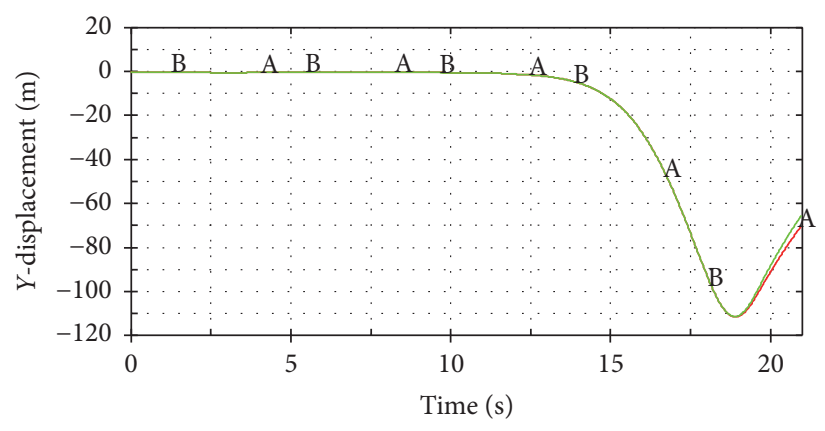

Node number

A. 5985

B 3034

(b) Time-history curves of vertical displacement

FIgURE 14: The displacement time-history curves of A and B nodes of girder deck.

is the biggest of all, followed by that of FM05 cable element and of FM01 cable element in turn. The further analysis of the cable-stayed bridge structure system can lead to the reasons for the cables axial force change law. Because the main pylon elements in the lower beam position begin to yield before the completely failure of the side piers, the girder dead load born by the lower beam is transferred to the cables near the main pylon resulting in the larger axial force fluctuation of the cables near main pylon and the smaller axial force fluctuation of the other side cables near the main pylon. Only several end cables show fracture failure in the collapse process of the whole structure system, so the cables fracture failure is not the main reason for the whole collapse of cable-stayed bridge structure.

4.2.4. Displacement Analysis of Girder Elements. Figures 14(a) and 14(b) represent the longitudinal displacement timehistory curve of node A and node B and the vertical displacement time-history curve of node $\mathrm{A}$ and node B, respectively. As shown in Figure 14, before the time of about $13 \mathrm{~s}$, the longitudinal displacement of node A and node B cause large fluctuation; however, the vertical displacement of node A and node B fluctuates within a small displacement range. Although there is large displacement occurring in the longitudinal direction, the whole structural system does not cause serious damage. The possible reason for that is that the large longitudinal displacement absorbs the earthquake energy resulting in the lagging of the structural failure. After the time of $13 \mathrm{~s}$, the longitudinal displacement and the vertical displacement all increase gradually and cause large displacement that indicates that the whole structural system causes serious damage, or even collapse.

\subsection{The Analysis Results under RSN13-H1 Seismic Wave}

4.3.1. Collapse Process Analysis of Cable-Stayed Bridge. The amplified RSN13-H1 seismic wave was applied to the finite element model of Daxiao Liandao cable-stayed bridge to simulate the whole process in which the structure began to damage to rose steadiness and eventually the collapse failure was observed. The whole collapse process is shown in Figure 15.

It can be obtained from the dynamic collapse process and the analysis results that all components of the cable-stayed bridge are within linear elastic conditions before $1 \mathrm{~s}$ and the whole structure is in well condition (Figure 15(a)) because of the smaller peak ground motion at begin of the seismic wave. With the continuously input of ground motion energy as well as the steady accumulation of structural damage, the first failure element occurs at the bottom of S02 auxiliary pier at time $3.96 \mathrm{~s}$ and the bottom elements of S02/S05 auxiliary pier step into completely yielding state at time $4.8 \mathrm{~s}$ (Figure 15(b)). The damage keeps on developing after the failure of auxiliary piers under seismic excitation, and the auxiliary pier bearings come into failure state which is evident at time $6.78 \mathrm{~s}$ (Figure 15(c)). Further destruction of cablestayed bridge leads to S01/S06 side pier bottom elements beginning to yield at time $11.08 \mathrm{~s}$, and the side pier bearings cause failure because of the excessive longitudinal displacement which reaches the maximum bearing displacement limit (Figure 15(d)). At time $15.92 \mathrm{~s}$, side piers are completely destroyed, the connection part between S03/S04 main pylon and lower cross beam begins to damage, and the cables do not show fracture damage (Figure 15(e)). At time $19.24 \mathrm{~s}$, the connection parts between S03/S04 main pylon and lower cross beam and the main pylon bottom completely yield resulting in the collapse of the main pylon, and the cables do not show fracture damage (Figure 15(f)). It can be noted that the main failure mode of the cable-stayed bridge subjected to longitudinal seismic wave includes the plastic damage at the bottom of auxiliary piers, side piers, and main pylons and at the connection part between main pylon and lower cross beam and the large deformation in the longitudinal direction.

4.3.2. Moment Time-History Analysis of Pylon Elements. It can be found from the moment time-history results of the main pylon elements in different positions that the elements failure occurs in the bottom position of the main pylons, in the lower cross beam position of the main pylons, and 


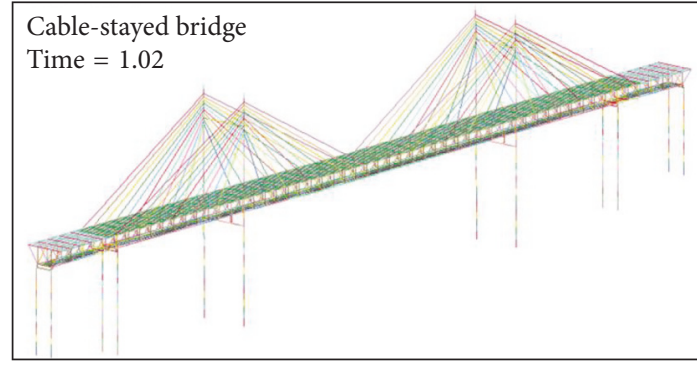

(a) Structure state at $1.02 \mathrm{~s}$

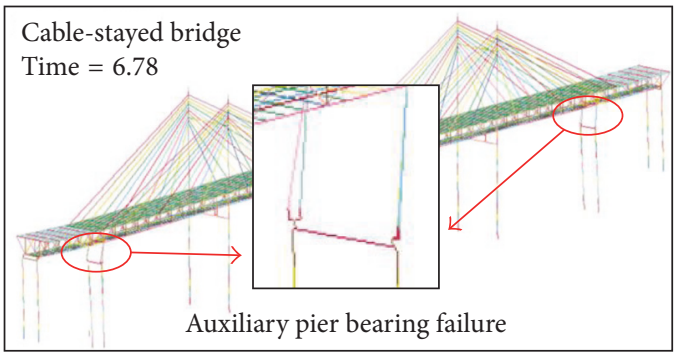

(c) Structure state at $6.78 \mathrm{~s}$

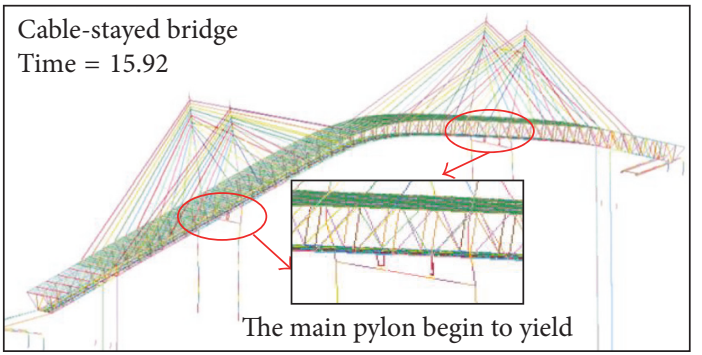

(e) Structure state at $15.92 \mathrm{~s}$

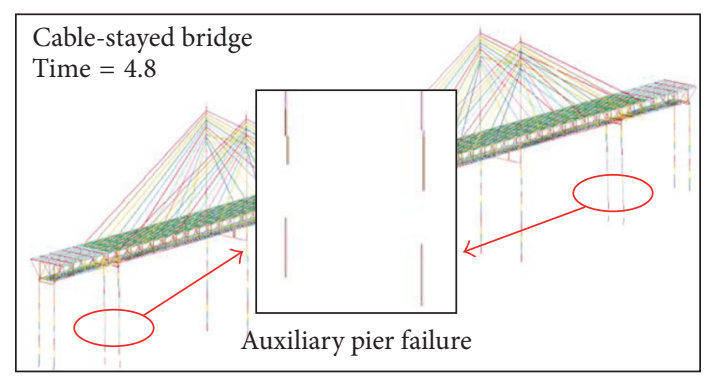

(b) Structure state at $4.80 \mathrm{~s}$

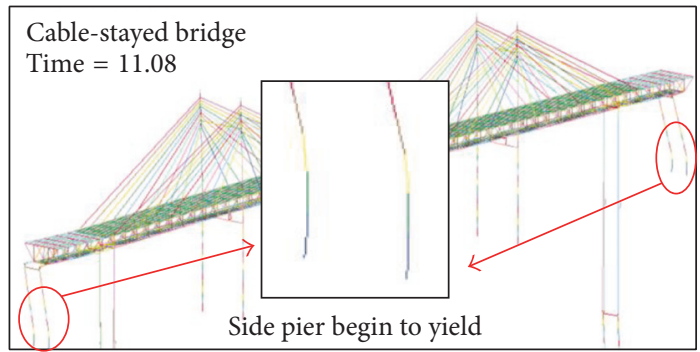

(d) Structure state at $11.08 \mathrm{~s}$

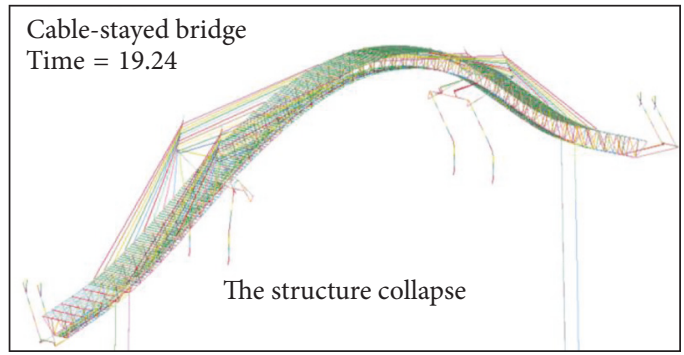

(f) Structure state at $19.24 \mathrm{~s}$

FIGURE 15: Collapse failure process under RSN13-H1 seismic wave.

in the upper cross beam position of the main pylons. Figures 16(a)-16(c) present the moment time-history curves of the elements in the three positions mentioned above, respectively. As shown in the figures, the elements moment will reduce to be zero at a specific time that indicates that the completely failure happens to the elements. It can be concluded from the elements failure time in the three positions that the elements failure is in a specific sequence beginning from the main pylon element in the lower cross beam position to the main pylon element in the upper cross beam position and finally to the main pylon element in the bottom position.

4.3.3. Axial Force Time-History Analysis of Cable Elements. Figures 16(d)-16(f) show the axial force time-history curves of FS01/FS05/FS10 cable elements, respectively. It can be seen from the axial force time-history curves of FS01, FS05, and FS10 cable elements that the axial force fluctuates within a certain range before the whole collapse of the cable-stayed bridge structure. Although there are obvious changes in axial force, the axial force does not exceed the ultimate bearing capacity of all the cables. It also can be known that the axial force fluctuation range of FS10 cable element is the biggest of all, followed by that of FS05 cable element and of FS01 cable element in turn. The same axial force change law is obtained for the other side cables (FM01, FM02, .., FM10) of S03 pylon. The further analysis of the cable-stayed bridge structure system can lead to the reasons for the cables axial force change law. Because of the failure of auxiliary piers and side piers, the vertical support at both ends of the girder is lost making the girder dead load born by auxiliary piers and side piers transfer to the end cables and resulting in the larger axial force fluctuation of the end cables. However the axial force fluctuation of the cables near the main pylon is influenced slightly. Only several end cables show fracture failure in the collapse process of the whole structure system, so the cables fracture failure is not the main reason for the whole collapse of cable-stayed bridge structure.

4.3.4. Displacement Analysis of Girder Elements. Figures 17(a) and $17(\mathrm{~b})$ represent the longitudinal displacement timehistory curve of node $\mathrm{A}$ and node $\mathrm{B}$ and the vertical displacement time-history curve of node A and node B, respectively. As shown in Figure 17, the longitudinal displacement and the vertical displacement of node A and node B fluctuate within a certain displacement range before about $10 \mathrm{~s}$ that indicates 


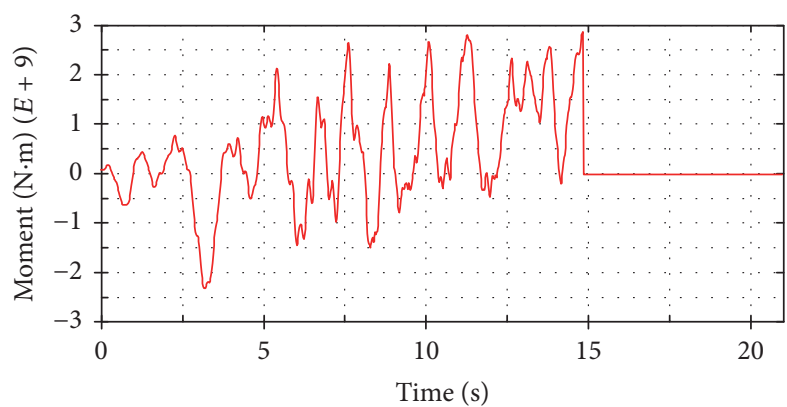

(a) The moment time-history curve of the pylon element in the lower cross beam position

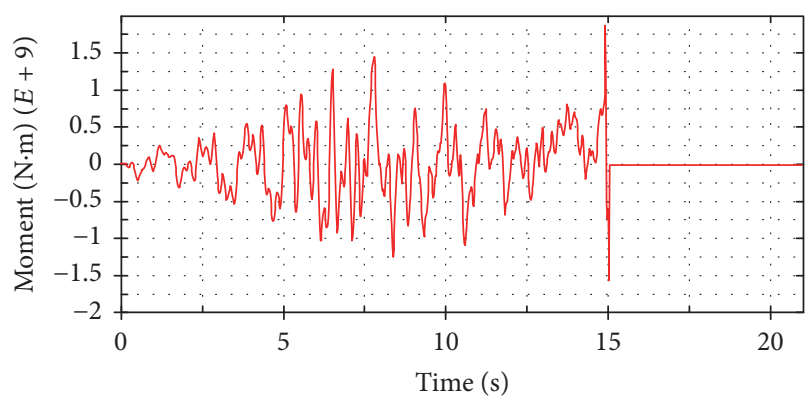

(c) The moment time-history curve of the pylon element in the upper cross beam position

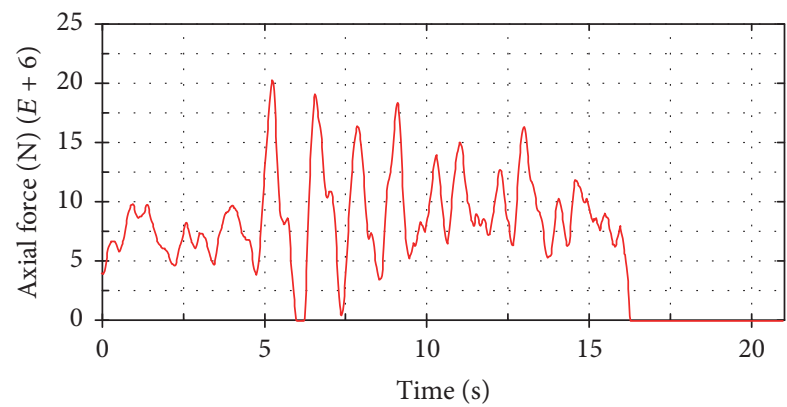

(e) The axial force time-history curve of FS05 cable element

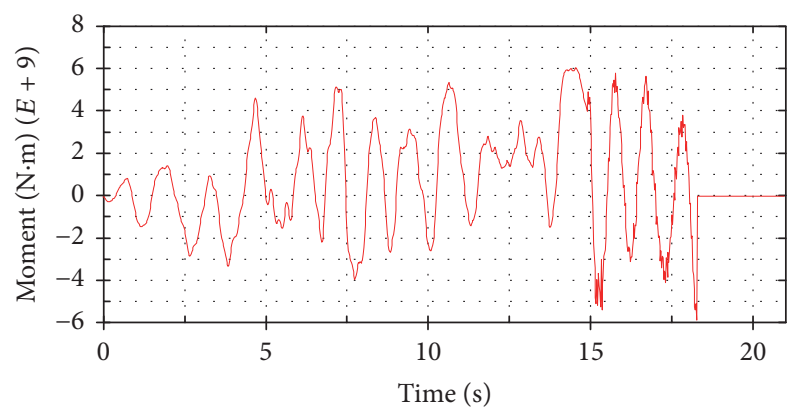

(b) The moment time-history curve of the pylon bottom element

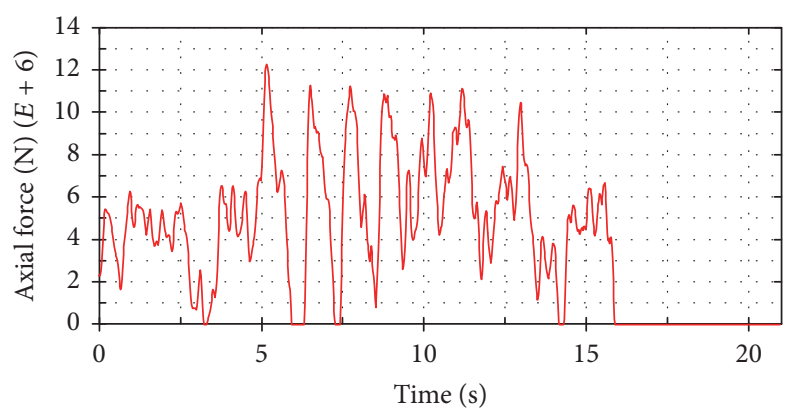

(d) The axial force time-history curve of FS01 cable element

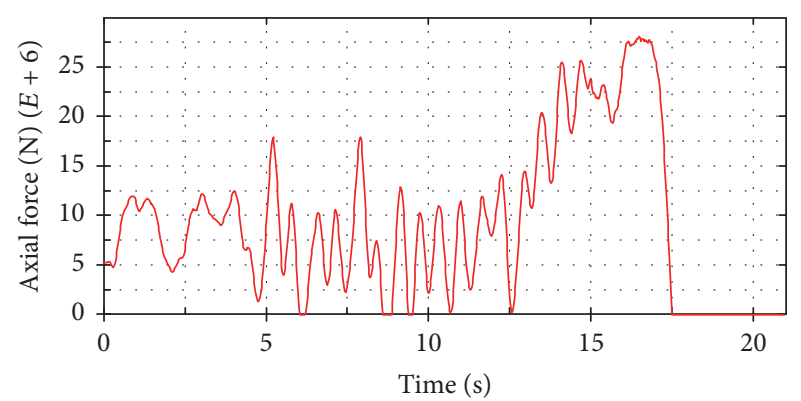

(f) The axial force time-history curve of FS10 cable element

FIGURE 16: Time-history curves of moment and axial force for elements.

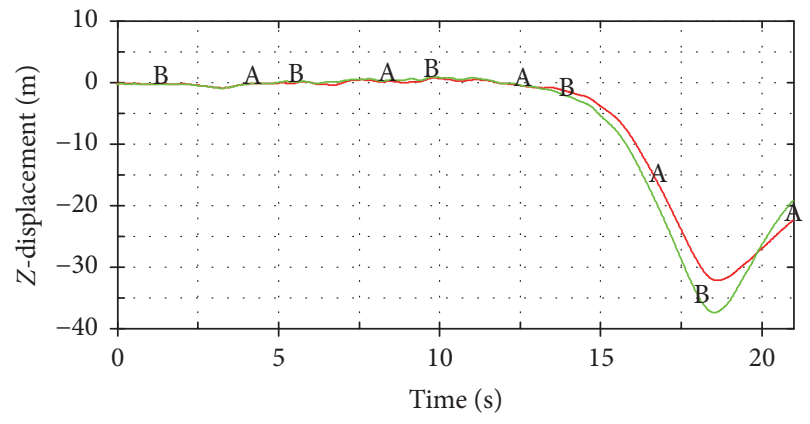

Node number

A 5985

(a) Time-history curves of longitudinal displacement

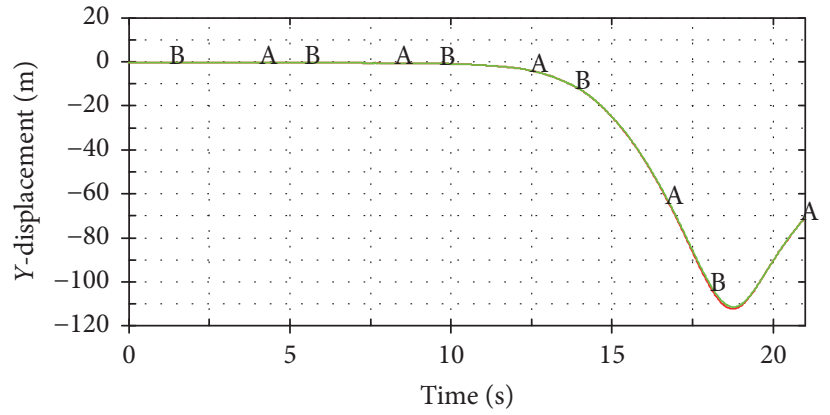

Node number

A. 5985

B 3034

(b) Time-history curves of vertical displacement

FIgURE 17: The displacement time-history curves of A and B nodes of girder deck. 
that the whole structural system does not cause serious damage. After the time of $10 \mathrm{~s}$, the longitudinal displacement and the vertical displacement all increase gradually and cause large displacement that indicates that the whole structural system causes serious damage, or even collapse.

\section{Conclusions}

The rail-cum-road steel truss cable-stayed bridge under construction in china is taken into an engineering background. The nonlinear dynamic analysis with application of the explicit dynamic FEM was performed to present the collapse process and failure mechanism of long-span cable-stayed bridges under strong seismic excitations. Three different seismic waves are chosen to investigate the influence of the random characteristics of seismic waves on collapse process and failure mechanism. According to the results presented in this study, some conclusions and suggestions are summarized as follows:

(1) The simulation of the whole collapse process of cable-stayed bridge structure can be carried out by explicit dynamic FEM. Explicit dynamic FEM has strong calculation ability of geometric nonlinear compared with implicit dynamic FEM. Meanwhile there is no convergence problem existing in the explicit dynamic FEM. But explicit central difference calculation method is conditionally stable; the stability condition for the central difference method is to satisfy (20). All in all, the explicit dynamic FEM has great advantage in the research on this kind of problems.

(2) It can be seen from the numerical simulation analysis that the whole collapse failure process and failure modes of the cable-stayed bridge structure under the three groups of seismic waves are similar. Firstly, the auxiliary piers cause failure resulting in the failure of bearings at the top of auxiliary piers. Secondly, the side piers step into the yielding situation; meanwhile the bearings at the top of side piers cause failure due to excessive longitudinal displacement beyond the bearing displacement limit. Finally, the collapse damage happens to the whole structure owing the failure of main pylons and a small amount of staycables are destroyed in the process of collapse.

(3) As we can know from the elements moment timehistory curves, elements failure of the main pylons in the bottom position, in the upper cross beam position, and in the lower cross beam position is the main reason for the collapse of the main pylons. Meanwhile the elements of main pylons in the lower cross beam position are the first to yield.

(4) It can be obtained from the cable elements axial timehistory curves that end cables have larger axial force fluctuation and are the easiest to cause fracture failure.

(5) It can be concluded from the analysis of the failure components in the process of cable-stayed bridge collapse that the critical components contributing to the collapse damage of the cable-stayed bridge structure and the components failure location include the auxiliary piers bottom, the side piers bottom, the side pier bearings, the connection part between main pylon and upper cross beam, the connection part between main pylons and lower cross beam, and the main pylons bottom. However, the cables are damaged during the whole structure collapse process because of the failure of the main pylons, so the failure of cables is not the main reason for the collapse failure of cable-stayed bridge. The analysis results can provide theoretical basis for collapse resistance design and seismic vulnerability analysis of long-span highway and railway cable-stayed bridges.

\section{Conflicts of Interest}

The authors declare that there are no conflicts of interest regarding the publication of this paper.

\section{Acknowledgments}

The authors gratefully acknowledge the financial support from the Research Project of Application Foundation in Sichuan Province of China (17YYJC0699/2017JY0003). The first author would also like to acknowledge the Chinese Scholarship Council (CSC) foundation for providing him with financial support to study abroad.

\section{References}

[1] B. H. Ji and Z. Q. Fu, "Analysis of Chinese bridge collapse accident causes in recent years," China Civil Engineering Journal, vol. 43, no. s1, pp. 495-498, 2010.

[2] F. Z. Dong, J. Guo, and Q. J. Wang, "Review of bridge collapse accidents and countermeasures," Shanghai Highway, vol. 2, article 38, no. 2, pp. 30-32, 2016.

[3] W. Zhiqiang and G. C. Lee, "A comparative study of bridge damage due to the Wenchuan, Northridge, Loma Prieta and San Fernando earthquakes," Earthquake Engineering and Engineering Vibration, vol. 8, no. 2, pp. 251-261, 2009.

[4] T. Kitada, "Ultimate strength and ductility of state-of-theart concrete-filled steel bridge piers in Japan," Engineering Structures, vol. 20, no. 4-6, pp. 347-354, 1998.

[5] W. Y. Liao, J. X. Luo, and X. Wan, "Responses of isolated bridges subjected to near-fault ground motions," Earthquake Engineering and Engineering Dynamics, vol. 21, no. 4, pp. 102$108,2001$.

[6] G. Shoji, J. Kitahara, A. Kojima, T. Kanakubo, K. Shimizu, and Y. Sakai, "Mechanism of seismic response of a PC cable-stayed bridge subjected to a long-period seismic excitation," Doboku Gakkai Ronbunshuu A, vol. 64, no. 4, pp. 982-1001, 2008.

[7] G. Shoji, T. Kogi, and Y. Umesaka, "Seismic response of a PC cable-stayed bridge subjected to a long-period ground motion," in Proceedings of the 14th World Conference on Earthquake Engineering, Beijing, China, October, 2008.

[8] J. Li, T. Peng, and Y. Xu, "Damage investigation of girder bridges under the Wenchuan earthquake and corresponding seismic design recommendations," Earthquake Engineering and Engineering Vibration, vol. 7, no. 4, pp. 337-344, 2008. 
[9] W. L. Zhuang, Z. Y. Liu, and J. S. Jiang, "Earthquake-induced damage analysis of highway bridges in wenchuan earthquake and countermeasure," Chinese Journal of Rock Mechanics and Engineering, vol. 28, no. 7, pp. 1377-1387, 2009.

[10] O. Norio, T. Ye, Y. Kajitani, P. Shi, and H. Tatano, "The 2011 eastern Japan great earthquake disaster: Overview and comments," International Journal of Disaster Risk Science, vol. 2, no. 1, pp. 34-42, 2011.

[11] K. Kawashima, K. Kosa, Y. Takahashi et al., "Damages of bridges during 2011 great East Japan earthquake," in Proceedings of the 43rd Joint Meeting, US-Japan Panel on Wind and Seismic Effects, UJNR, Tsukuba Science City, Japan, 2011.

[12] H. Hwang, J. Liu B, and H. Chiu Y, "Seismic fragility analysis of highway bridges," Tech. Rep., Center for Earthquake Research and Information, University of Memphis, Memphis, 2001.

[13] E. Choi, R. DesRoches, and B. Nielson, "Seismic fragility of typical bridges in moderate seismic zones," Engineering Structures, vol. 26, no. 2, pp. 187-199, 2004.

[14] A. R. Khan, S. Ahmad, and T. K. Datta, "Effect of soil-structure interaction on seismic risk of FAN type cable stayed bridges," Journal of Seismology and Earthquake Engineering, vol. 6, no. 2, pp. 47-56, 2004.

[15] R. A. Khan, T. K. Datta, and S. Ahmad, "A simplified fragility analysis of fan type cable stayed bridges," Earthquake Engineering and Engineering Vibration, vol. 4, no. 1, pp. 83-94, 2005.

[16] Y. Pan, A. K. Agrawal, M. Ghosn, and S. Alampalli, "Seismic fragility of multi-span simply supported steel highway bridges in New York State. II: fragility analysis, fragility curves, and fragility surfaces," Journal of Bridge Engineering, vol. 15, no. 5, pp. 462-472, 2010.

[17] M. Bayat, F. Daneshjoo, and N. Nisticò, "A novel proficient and sufficient intensity measure for probabilistic analysis of skewed highway bridges," Structural Engineering and Mechanics, vol. 55, no. 6, pp. 1177-1202, 2015.

[18] M. Bayat, F. Daneshjoo, and N. Nisticò, “The effect of different intensity measures and earthquake directions on the seismic assessment of skewed highway bridges," Earthquake Engineering and Engineering Vibration, vol. 16, no. 1, pp. 165-179, 2017.

[19] S. K. Kunnath and J. L. Gross, "Inelastic response of the cypress viaduct to the Loma Prieta earthquake," Engineering Structures, vol. 17, no. 7, pp. 485-493, 1995.

[20] F. Zayati, S. A. Mahin, and J. P. Moehle, Experimental and Analytical Evaluation of A Retrofit Double-Deck Viaduct Structure, Earthquake Engineering Research Center, University of California, 1996.

[21] K. Z. Xie and L. M. Sun, "Study on collapse-mechanism of long span and high-pier continuous rigid frame bridges during strong earthquake," in Proceedings of the 14th World Conference on Earthquake Engineering, Beijing, China, October, 2008.

[22] H. Wibowo, Progressive Collapse Analysis of Reinforced Concrete Bridges during Earthquakes [Master, thesis], University of Ottawa, Canada, 2009.

[23] Z. Zong, Z. Xia, H. Liu, Y. Li, and X. Huang, "Collapse failure of prestressed concrete continuous rigid-frame bridge under strong earthquake excitation: Testing and simulation," Journal of Bridge Engineering, vol. 21, no. 9, Article ID 04016047, 2016.

[24] Z. X. Li, Y. Chen, and N. Li, "Collapse analysis of RC continuous girder bridge under strong earthquakes," Earthquake Engineering and Engineering Vibration, vol. 36, no. 1, pp. 35-43, 2016.

[25] K.-Z. Xie, H.-Y. Lin, and S.-S. Yang, "Collapse-mechanism of concrete filled steel tube arch bridge during strong earthquake," in Proceedings of the 2010 International Conference on Mechanic Automation and Control Engineering, MACE2010, pp. 977-981, chn, June 2010.

[26] L. L. Song, Three-Dimensional Modeling And Collapse Simulation Analysis of Arch Bridge [Master, thesis], Zhejiang University of Technology, China, 2009.

[27] H. Yoo, H.-S. Na, and D.-H. Choi, "Approximate method for estimation of collapse loads of steel cable-stayed bridges," Journal of Constructional Steel Research, vol. 72, pp. 143-154, 2012.

[28] Y. F. Duan, K. He, H. M. Zhang et al., "Entire-process simulation of earthquake-induced collapse of a mockup cable-stayed bridge by vector form intrinsic finite element (VFIFE) method," Advances in Structural Engineering, vol. 17, no. 3, pp. 347-360, 2014.

[29] Z.-H. Zong, R. Zhou, X.-Y. Huang, and Z.-H. Xia, "Seismic response study on a multi-span cable-stayed bridge scale model under multi-support excitations. Part I: shaking table tests," Journal of Zhejiang University SCIENCE A, vol. 15, no. 5, pp. 351363, 2014.

[30] R. Zhou, Z.-H. Zong, X.-Y. Huang, and Z.-H. Xia, "Seismic response study on a multi-span cable-stayed bridge scale model under multi-support excitations. Part II: numerical analysis," Journal of Zhejiang University: Science A, vol. 15, no. 6, pp. 405418, 2014.

[31] Z. H. Zong, X. Y. Huang, Y. L. Li, and Z. H. Xia, "Evaluation of the collapse failure modes of cable-stayed bridge model under strong earthquake excitations," China Science Paper, vol. 11, no. 7, pp. 721-727, 2016.

[32] X. C. Wang, Finite Element Method, Tsinghua University Press, Beijing, China, 2003.

[33] J. O. Hallquist, LS-DYNA Theory Manual, Livermore Software Technology Corporation, 2006.

[34] C. Zhou, Research on the Whole Collapse Process of Simulation Analysis of Reinforced Concrete Bridge under Seismic Excitation [Ph.D. thesis], Tongji University, China, 2003.

[35] L. C. Fan, Anti -Seismic Design on Large -Span Bridges, Peoples Communication Press, Beijing, China, 2001. 


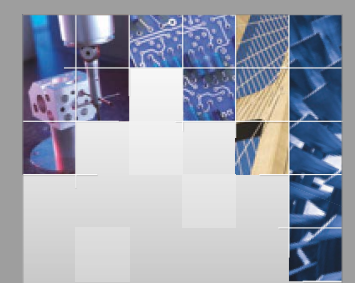

\section{Enfincering}
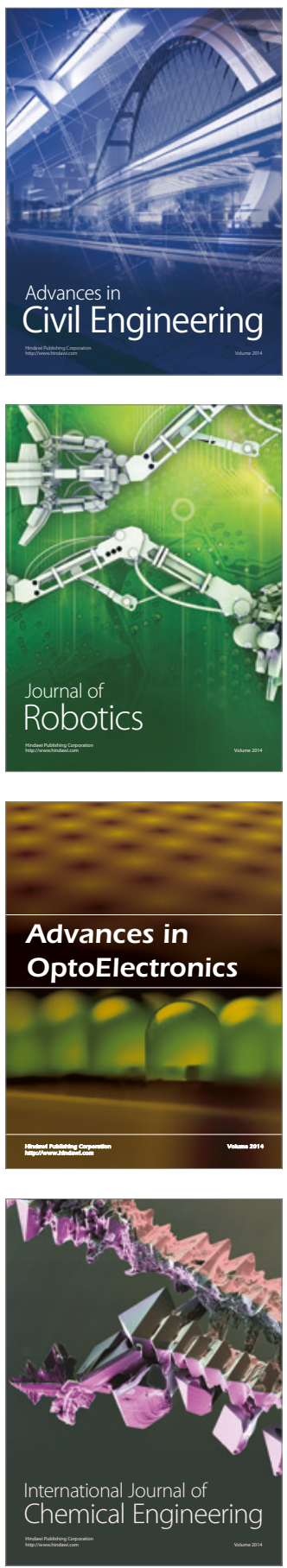

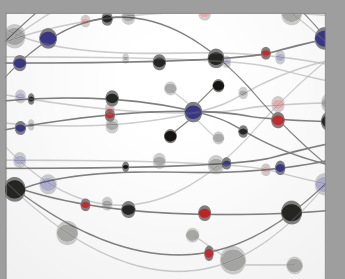

The Scientific World Journal

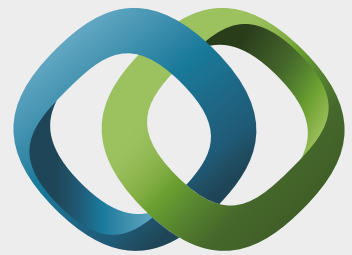

\section{Hindawi}

Submit your manuscripts at

https://www.hindawi.com
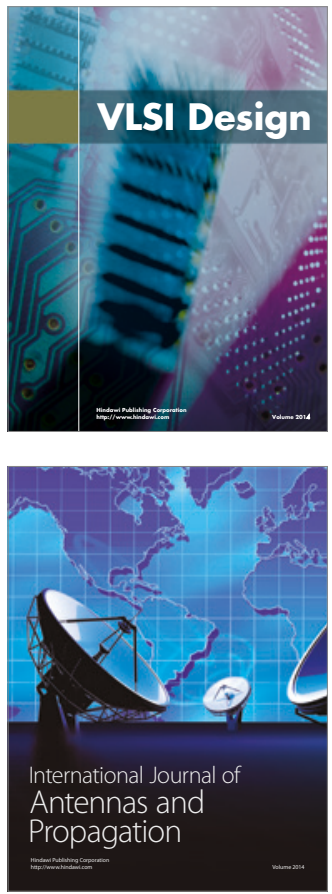

\section{Rotating}

Machinery
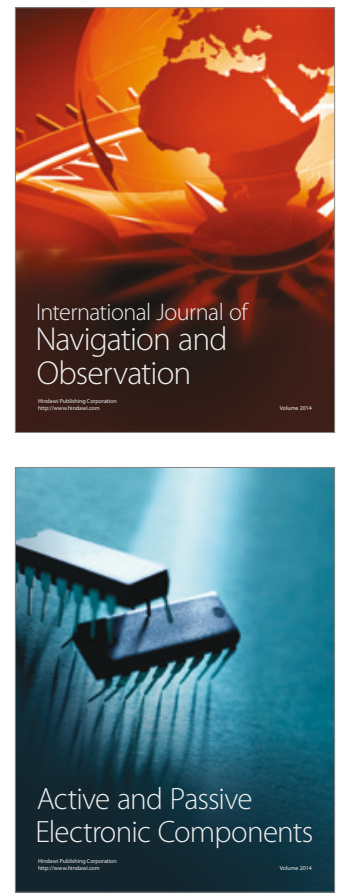
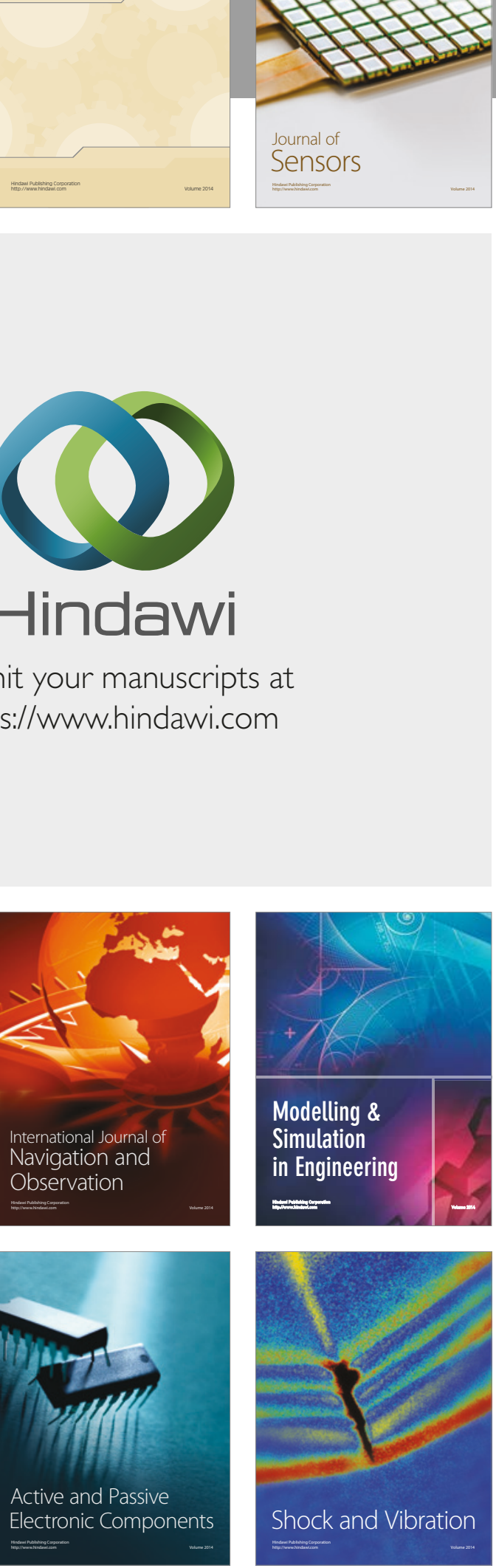
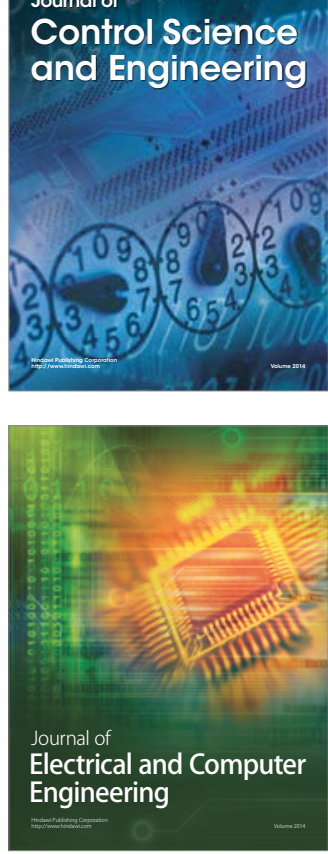

Distributed

Journal of

Control Science

and Engineering
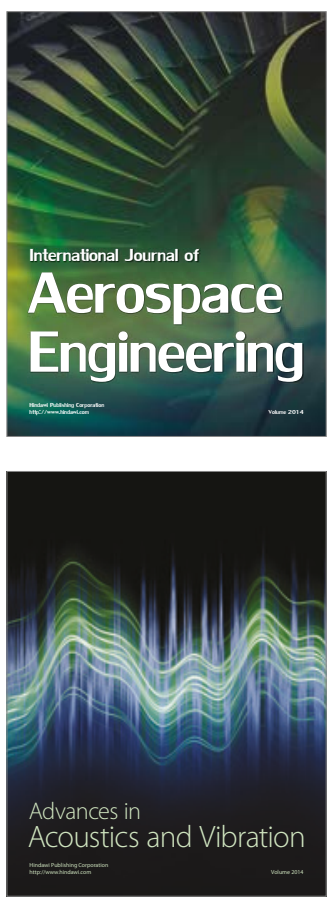

Sensor Networks 